\title{
Protocolo quirúrgico en la reconstrucción de la parálisis facial: nuestra experiencia tras 140 casos tratados
}

\section{Protocol in surgical treatment of facial paralysis after 140 treated cases}

\author{
Hontanilla Calatayud, B.*, Aubá Guedea, C.*, Vila Sobral, A.**, Castro García, J.**, \\ San Martín Maya, A.**, Botellé del Hierro, J .**, Rodríguez Losada, G.**, \\ Gómez Ruiz, R.**, Bazán Álvarez, A.*
}

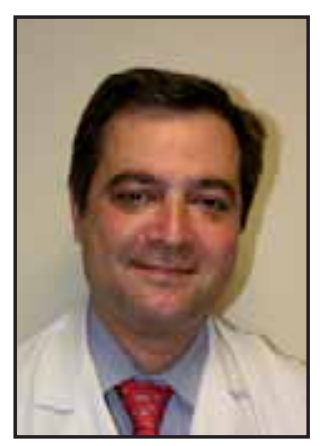

Hontanilla, B.

\section{Resumen}

El objetivo de este trabajo es presentar nuestro protocolo de actuación en el tratamiento quirúrgico de la parálisis facial tras 140 casos tratados entre los años 2000 y 2007. Este protocolo está basado en los resultados obtenidos con un nuevo sistema de captura del movimiento facial en 3D denominado "Facial Clima", que puede ser considerado como un método objetivo de medición de los resultados en la cirugía de reanimación facial. Así podría compararse en pacientes con parálisis facial, la efectividad de los tratamientos entre distintos centros. Exponemos los resultados obtenidos tanto a nivel de la reconstrucción de la sonrisa como a nivel palpebral.

$\begin{aligned} \text { Palabras clave } & \text { Parálisis facial. Análisis movimiento } \\ & \text { facial. }\end{aligned}$
Código numérico $257-2576$

\begin{abstract}
The aim of this study is to present our protocol in the surgical treatment of facial paralysis after 140 treated cases since 2000 to 2007 . The protocol is based on the results obtained with a new 3-D capture system of the facial movement called "Facial Clima", that could be considered as the adequate tool to assess the outcome of the facial paralysis reanimation surgery. Thus, patients with facial paralysis could be compared among surgical centres such that effectiveness of facial reanimation operations could be evaluated. The results obtained are exposed for smile and lid reconstruction.
\end{abstract}

$\begin{array}{ll}\text { Key words } & \text { Facial paralysis treatment. Facial move- } \\ & \text { ment analysis. } \\ \text { Numeral Gode } & 257-2576\end{array}$




\section{Introducción}

Un paciente que presenta una parálisis facial requiere de un plan de tratamiento basado en las deformidades particulares y en sus propias preocupaciones. Atendiendo al nivel anatómico de la lesión del nervio (en su porción intracraneal, a nivel del hueso temporal o en su porción extracraneal), los intentos de rehabilitar una lesión del nervio facial se focalizan en tres áreas: la restauración de la función protectora de los párpados para prevenir la exposición corneal, la reconstrucción de la incontinencia oral del labio inferior y la restauración de la sonrisa. Sin embargo, la multitud de técnicas existentes en la reconstrucción estática y dinámica de la parálisis facial es tan grande como la variabilidad de los resultados obtenidos dependiendo de los cirujanos que las emplean. De esta manera, para comparar la efectividad de las diferentes técnicas quirúrgicas o incluso para comparar la utilización de diferentes trasplantes musculares libres o pediculados en la rehabilitación dinámica de la parálisis facial, es necesario un sistema cuantitativo validado. El mayor problema cuando se comparan los resultados obtenidos, es que cada cirujano utiliza diferentes métodos para evaluar los resultados haciendo por tanto que las comparaciones sean casi imposibles.

Para resolver este problema, se han desarrollado métodos cualitativos fáciles de aplicar, pero que tienen resultados diferentes entre observadores y entre sujetos. Los métodos clásicamente utilizados son el sistema de House-Brackmann o el Sydney y el Sunnybrook Facial Grading System (SFGS) (1-4); sin embargo, estas escalas son ambiguas y subjetivas. Los grados oscilan de forma arbitraria de leve a grave y la distancia entre grados no siempre es igual. Además no aportan información dinámica sobre el movimiento Para resolver estos problemas se han creado diferentes sistemas informáticos que miden el movimiento facial mediante puntos marcados en la piel de la cara (5-10), cuantifican pixels $(11,12)$, observan las variaciones en la reflección de la luz (13), o el dibujo de líneas en la superficie de la cara (14) a través de fotografías $(8,11,15)$ o grabaciones en vídeo $(5-7,9,10)$. A pesar de todo, estos métodos aportan principalmente información estática, son técnicas que requieren tiempo para llevarlas a cabo y ninguna de ellas aporta información tridimensional de los vectores faciales.

En la Unidad de Parálisis Facial de la Clínica Universitaria de Navarra, hemos desarrollado un sistema que aporta información dinámica y automática del movimiento facial de forma tridimensional denominado "facial Clima" (16). La aplicación de este sistema a 140 pacientes afectos de parálisis facial desde el año 2000 al 2007 nos ha permitido realizar un proto- colo de tratamiento en la reconstrucción estática y dinámica de la parálisis facial.

\section{Pacientes y método}

"Facial Clima" es un sistema óptico automático de captación del movimiento facial que requiere la implantación de pequeños puntos reflectantes en la cara del paciente siguiendo una configuración determinada. Un sistema de vídeo recoge el movimiento con la ayuda de tres cámaras con luz infrarroja, mientras el paciente sonríe, abre y cierra los ojos y sube las cejas. Las imágenes de las cámaras son automáticamente procesadas con un software especial que genera todo tipo de gráficas e información tridimensional, incluyendo la velocidad del movimiento y las áreas entre vectores. La exactitud del proceso de medición está entre $0.13 \mathrm{~mm}$ y 0.41 grados.

Este sistema ha sido testado en pacientes normales, con una fiabilidad del 99\% (16) (para mayor información sobre el funcionamiento del sistema consúltese la referencia). Los resultados que exponemos en este artículo han sido cuantificados mediante este sistema en 140 pacientes afectos de parálisis facial tratados desde el año 2000 hasta el 2007 (Tabla I).

Resultados

Los resultados obtenidos en los grupos funcionales más representativos (Injerto Facial Cruzado (IFC), trasplante muscular y transposición del músculo temporal) se muestran en las Tablas II, III y IV respectivamente; se ha obtenido la media de cada grupo y los resultados son meramente descriptivos. Junto con la valoración numérica se ha tenido en cuenta el grado de satisfacción del paciente y del cirujano.

\section{Discusión}

\section{PROTOCOLO DE ACTUACION EN LA REHABILITACION DE LA SONRISA}

\section{Técnicas de injerto y neurorrafia}

Las técnicas de neurorrafia e injerto son una parte esencial de la cirugía rehabilitadora de la parálisis facial. De hecho, la habilidad para realizar algún procedimiento de neurorrafia determina muchas veces la necesidad o no de llevar a cabo otras técnicas quirúrgicas con posterioridad. Está indicada una neurorrafia del nervio facial cuando existe una pérdida completa de función del mismo, ya sea por discontinuidad anatómica o por degeneración neural irreversible y existan tubos neurales distales competentes, la musculatura facial no se encuentre atrofiada (tiempo de evolución 
Tabla I. Casos de parálisis facial tratados en nuestro Centro desde el año 2000 al 2007.

RECONSTRUCCIÓN PALPEBRAL
Colocación pesa de oro párpado superior
Colocación tendón párpado inferior
Cantoplastia externa
RECONSTRUCCIÓN DE LA SONRISA
Injerto facial directo
Injerto facial cruzado
Transposición hemihipogloso-facial
Transposición maseterino-facial
Transplante muscular microquirúrgico $\left(a c i l i_{\mathfrak{s}}\right)+$ injerto facial cruzado
Transplante muscular microquirúrgico $\left(l a i_{s} i m_{r} d o\right.$ One
Trasposición de músculo temporal
Colocación Tendón facial

$\mathrm{N}=86$
65
24
13
$\mathrm{~N}=140$
12
26
17
2
47
1
9
26

Tabla II. Resultados medios obtenidos con el medidor automático ("Facial Clima") en los casos tratados mediante injerto facial cruzado.

\begin{tabular}{lcccc}
\hline Injerto facial cruzado $(\mathrm{N}=26)$ & $\begin{array}{c}\text { Media cuando contrae } \\
\text { (Lado normal) }\end{array}$ & $\begin{array}{c}\text { Media cuando relaja } \\
\text { (Lado normal) }\end{array}$ & $\begin{array}{c}\text { Media cuando contrae } \\
\text { (Lado reconstruido) }\end{array}$ & $\begin{array}{c}\text { Media cuando relaja } \\
\text { (Lado reconstruido) }\end{array}$ \\
Vector cigomático $(\mathrm{mm})$ & 69,1 & 82,6 & 80,5 & 84,4 \\
Ángulo de Sonrisa & $130^{\circ}$ & $128^{\circ}$ & $139^{\circ}$ & $127^{\circ}$ \\
Área de mejilla $\left(\mathrm{mm}^{2}\right)$ & 3046 & 3515 & 3508 & 3183 \\
Velocidad del segmento cigomático $(\mathrm{mm} / \mathrm{s})$ & 65 & 46,9 & 45,1 & 33,7
\end{tabular}

Tabla III. Resultados medios obtenidos con el medidor automático ("Facial Clima") en los casos tratados mediante injerto facial cruzado y trasplante muscular con acili $i_{\mathfrak{s}}$ en dos tiempos quirúrgicos.

\begin{tabular}{lcccc}
\hline $\begin{array}{l}\text { Trasplante muscular } \\
\text { microquirúrgico }(\mathrm{n}=47)\end{array}$ & $\begin{array}{c}\text { Media cuando contrae } \\
\text { (Lado normal) }\end{array}$ & $\begin{array}{c}\text { Media cuando relaja } \\
\text { (Lado normal) }\end{array}$ & $\begin{array}{c}\text { Media cuando contrae } \\
\text { (Lado reconstruido) }\end{array}$ & $\begin{array}{c}\text { Media cuando relaja } \\
\text { (Lado reconstruido) }\end{array}$ \\
Vector cigomático $(\mathrm{mm})$ & 65,8 & 81,5 & 74,3 & 84,2 \\
Ángulo de Sonrisa & $133^{\circ}$ & $130^{\circ}$ & $132^{\circ}$ & $125^{\circ}$ \\
Área de mejilla $\left(\mathrm{mm}^{2}\right)$ & 2800 & 3600 & 2779 & 3043 \\
Velocidad del segmento cigomático $(\mathrm{mm} / \mathrm{s})$ & 60,2 & 46,6 & 42,1 & 30,7
\end{tabular}

Tabla IV. Resultados medios obtenidos con el medidor automático ("Facial Clima”) en los casos tratados mediante transposición de músculo temporal.

$\begin{array}{lcccc}\text { Trasposición del temporal }(\mathrm{N}=9) & \begin{array}{c}\text { Media cuando contrae } \\ \text { (Lado normal) }\end{array} & \begin{array}{c}\text { Media cuando relaja } \\ \text { (Lado normal) }\end{array} & \begin{array}{c}\text { Media cuando contrae } \\ \text { (Lado reconstruido) }\end{array} & \begin{array}{c}\text { Media cuando relaja } \\ \text { (Lado reconstruido) }\end{array} \\ \text { Vector cigomático }(\mathrm{mm}) & 76,1 & 87,6 & 80,5 & 84,4 \\ \text { Ángulo de Sonrisa } & 133^{\circ} & 125^{\circ} & 132^{\circ} & 129^{\circ} \\ \text { Área de mejilla }\left(\mathrm{mm}^{2}\right) & 3120 & 3500 & 3408 & 3387 \\ \text { Velocidad del segmento cigomático }(\mathrm{mm} / \mathrm{s}) & 54 & 47,9 & 40,1 & 32,7\end{array}$

menor de 3 años, sobre todo en mujeres) y no exista ninguna posibilidad de recuperación espontánea.

La elección de la técnica de neurorrafia a utilizar depende de factores que son únicos para cada situación y paciente, por lo que resulta imprescindible individualizar cada caso. Entre estos factores se incluyen el tiempo transcurrido desde la lesión nerviosa, la infección o contaminación de la herida, la disponibilidad y viabilidad del extremo proximal y de los tubos neurales distales y el grado de atrofia muscular existente. Además, se deben considerar otros factores fisiológicos, psicológicos y sociológicos a la hora de elegir una técnica de neurorrafia.

Cuando se produce una sección del nervio facial traumática o yatrógena se debe realizar una reparación nerviosa primaria siempre y cuando se realice sin tensión y en una herida limpia. Durante las primeras 72 horas los extremos distales aún responden a la estimulación eléctrica, resultando más sencilla su identificación. En el caso de heridas infectadas o altamente contaminadas que requieran un cierre secundario, se deben marcar los extremos nerviosos y diferir la anastomosis, requiriendo generalmente técnicas de inmovilización e injertos de interposición para reparar la lesión debido a la retracción de los extremos y al edema tisular periférico.

En los pacientes cuya parálisis se instauró progresivamente o en aquellos en los que no es posible cono- 

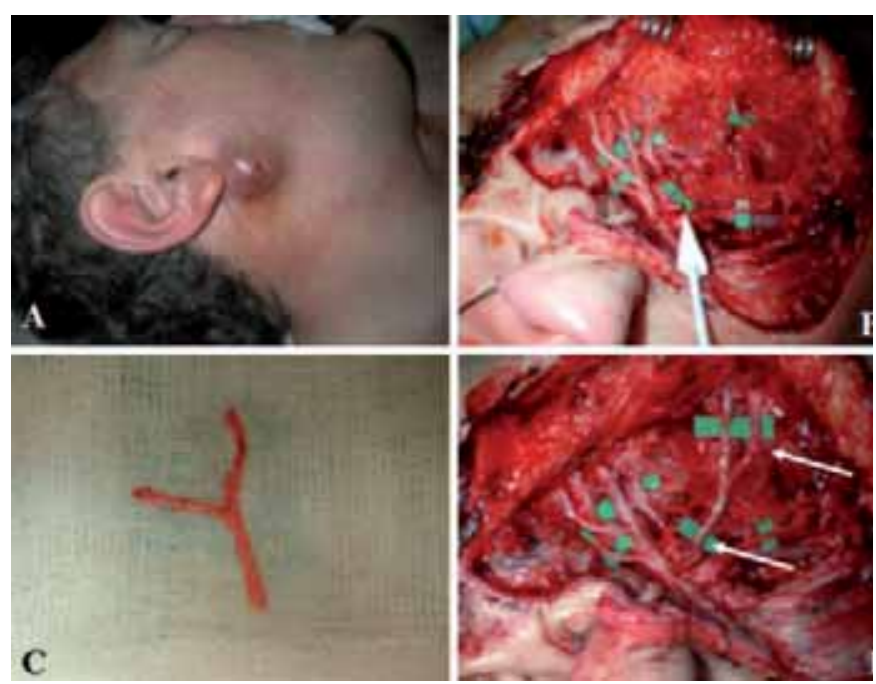

Fig. 1. A. Adenoma pleomorfo de parótida recidivado con afectación cutánea. B. Tras la resección tumoral, resecamos el tronco principal cigomático. C. Injerto de nervio auricular mayor para resolver el defecto. D. Las flechas apuntan al injerto interpuesto.
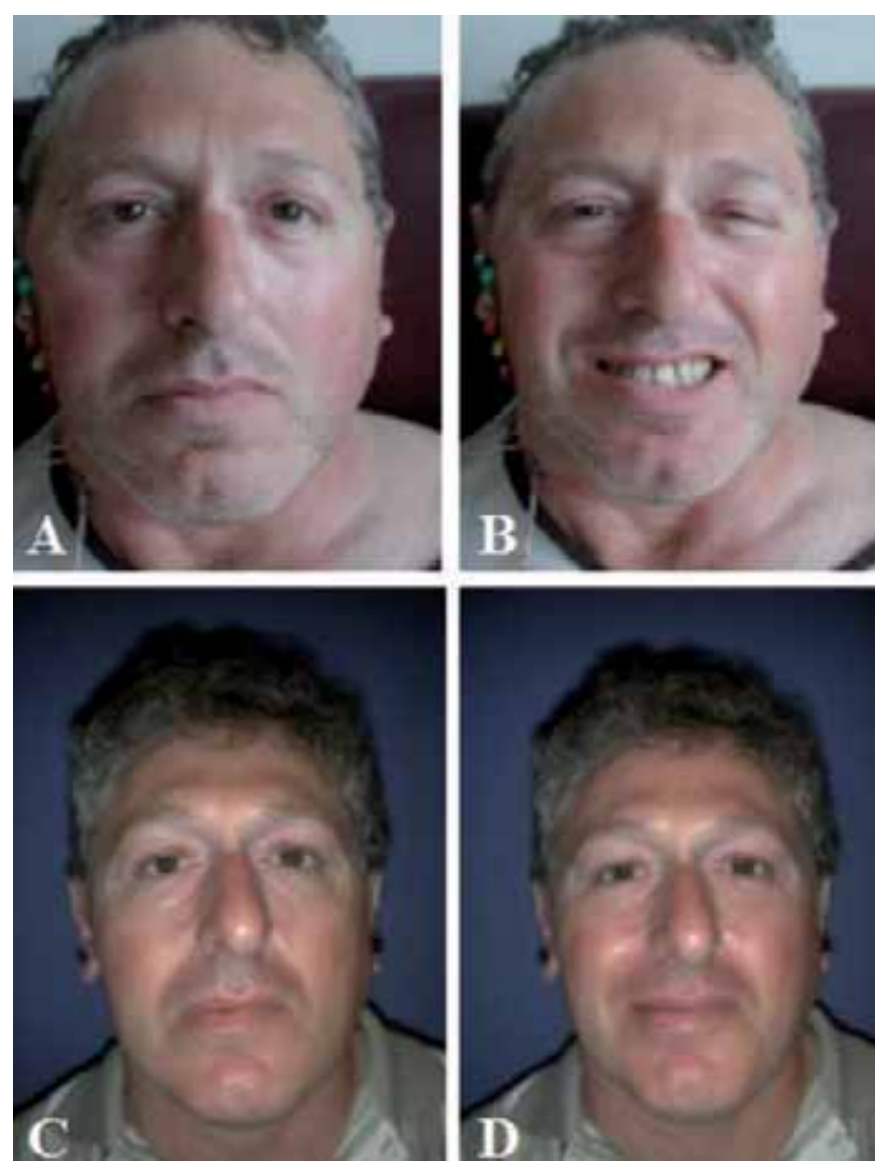

Fig. 2. El paciente de la figura anterior tras la cirugía en reposo (A) y sonriendo (B). Se puede observar el déficit de arrastre parcial del labio superior. El mismo paciente un año después de la interposición del injerto en reposo (C) y sonriendo (D).

cer la situación anatómica del nervio facial, se considera prudente un tiempo de observación de un año. Durante este tiempo se deben realizar pruebas electrofisiológicas que nos orienten sobre la integridad del nervio facial y los procesos de degeneración-regeneración que se estén produciendo, teniendo en cuen-
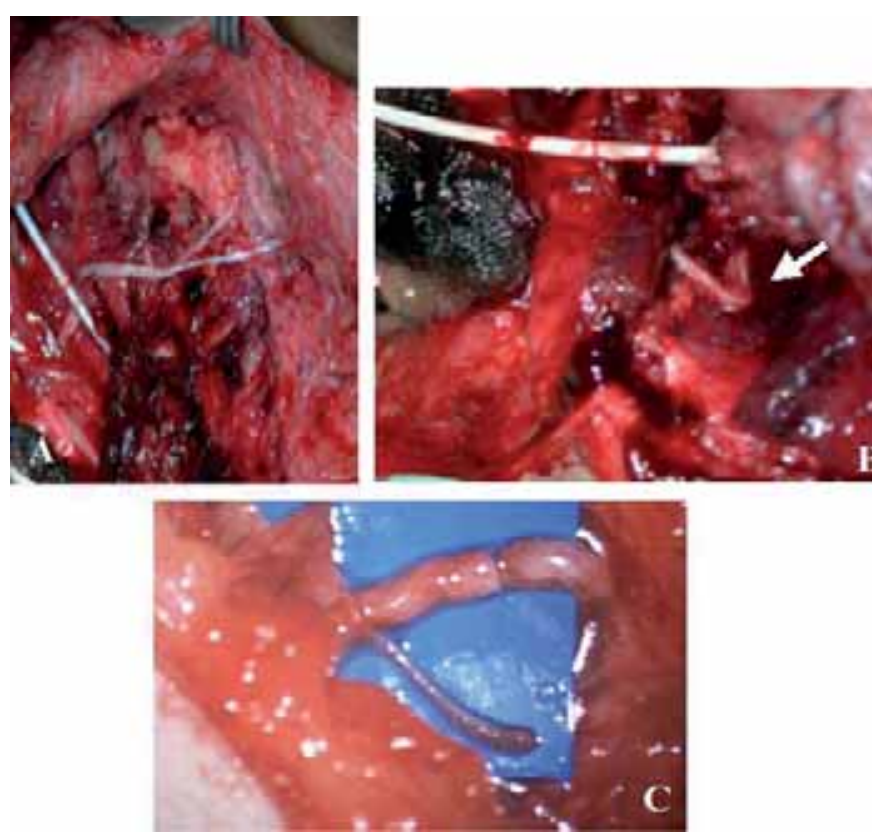

Fig. 3. Cuando La resección es más amplia se requiere de un injerto de sural cuyo cabo distal se conecta al muñón distal del nervio facial en el peñasco del temporal (Flecha) (B) y el cabo proximal se conecta a dos ramas distales cigomáticas del lado lesionado (A). Detalle de la anastomosis nerviosa de dos fascículos del nervio sural y dos ramas cigomáticas (C). Injerto rodeando la zona de irradiación prevista por de braquiterapia.
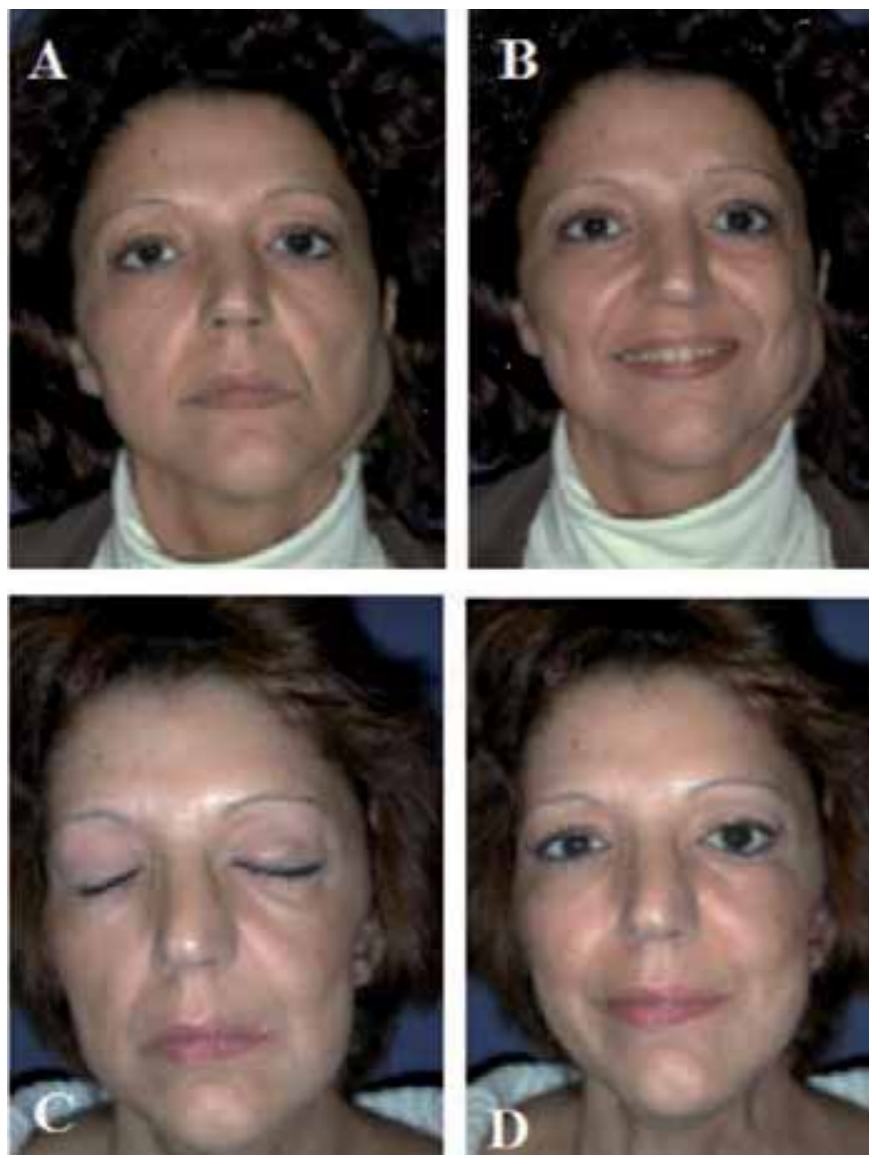

Fig. 4. Mujer de 46 años con cilindroma parotídeo izquierdo que provoca mínima paresia facial (A reposo y B sonriendo). Se realizó parotidectomía total y vaciamiento funcional ipsilateral con lesión total del nervio facial. Dos años después de la implantación de una pesa de oro en el párpado superior, presenta buen cierre palpebral y correcta activación de la sonrisa (C y D). 
ta que la realización de un injerto facial cruzado resulta poco eficaz pasados los 3 primeros meses. Después de un año, si no se resuelve la parálisis facial y no existen evidencias de reinervación en el electromiograma, es muy poco probable que la función facial se normalice espontáneamente, por lo que están indicadas las técnicas de neurorrafia anteriormente descritas. Pasados 2 años de la lesión inicial, los resultados de las técnicas de neurorrafia resultan menos fiables debido a la fibrosis neural, la obstrucción de los tubos neurales y a la atrofia muscular. En estos casos se debe realizar una biopsia del nervio facial previa a la realización de cualquier técnica de neurorrafia, estando ésta contraindicada en los casos en los que el nervio facial este completamente fibrosado, situación en la que deberemos considerar otras alternativas terapéuticas.

\section{Neurorrafia facial ipsilateral}

Consiste en reaproximar los extremos seccionados del nervio facial o, en el caso de que exista un defecto nervioso, colocar un injerto entre los dos extremos utilizando generalmente como zona donante del injerto nervioso el nervio auricular mayor o el nervio sural. Esta técnica constituye el tratamiento de elección para lesiones de ramas aisladas del facial, con una regeneración potente y rápida (Fig. 1-4). Sin embargo, una neurorrafia ipsilateral con injerto al tronco principal del facial, se sigue indefectiblemente de sincinesias y movimientos faciales en masa.

\section{Injerto nervioso facial cruzado}

La técnica de injerto nervioso facial cruzado (INFC), consiste en utilizar injertos de interposición para conectar ramas del nervio facial sano al nervio facial del lado contralateral paralizado y fue descrita por Scaramella y Anderl en 1970 (17).

El INFC permite que el nervio facial sano envíe impulsos motores sincronizados, simétricos y voluntarios al lado paralizado, consiguiendo así una expresión facial simétrica y espontánea. Como desventajas incluye: el largo tiempo requerido para la reinervación y el limitado número de axones motores donantes, siendo considerado como un nervio donante motor débil, por lo que se obtienen los mejores resultados si se realiza en los primeros 3 meses después del inicio de la parálisis facial y sobre todo en pacientes jóvenes. Especial cuidado debe ponerse en el momento de identificar las ramas donantes del nervio facial sano; éstas habitualmente deben ser dos y deben provocar en el lado sano el mismo movimiento que en el futuro provocarán en el lado paralizado. Generalmente no dejan déficit en la zona donante si se eligen correctamente; sin embargo, aunque algunos pacientes desarrollan una contracción muscular en el lado parali- zado, la cantidad de movimiento producido es inadecuado para satisfacer al paciente o al propio cirujano. Esto puede deberse a factores como: un largo periodo de denervación con atrofia muscular facial, un inadecuado injerto nervioso que no provoca reinervación potente o la mezcla de mensajes que han sido recolectados por el injerto nervioso que después es suturado a muchas ramas del nervio facial (Fig. 5 y 6 ).

Para evaluar el momento en el que las fibras nerviosas faciales regeneradas han alcanzado el lado contralateral es necesario realizar una exploración física buscando el signo de Tinnel, que consiste en la aparición de parestesias en el lado sano al percutir digitalmente el lado enfermo. La intensidad de las parestesias se corresponde con la eficacia de la regeneración.

\section{Transposiciones nerviosas}

Las transposiciones nerviosas se realizan en casos de daño irreversible del nervio facial y en ellas se toman otros nervios motores ipsilaterales como donantes de fibras motoras para poder restaurar en la medida de lo posible un movimiento voluntario del lado afecto. Se emplean cuando se desestima el injerto facial cruzado.

Los nervios que se suelen utilizar como donantes son el hipogloso (XII) y la rama motora del trigémino (V), quedando el uso del espinal accesorio (XI) como técnica histórica. Éstos se seccionan parcial o completamente y se anastomosan al extremo distal del nervio facial paralizado bien directamente o por medio de un injerto nervioso. Existen dos tipos de desventajas claras con este tipo de técnicas. En primer lugar, las derivadas de la morbilidad asociada a la sección del nervio donante (atrofia lingual y dificultad en la deglución en el caso del hipogloso; escápula alada en el caso del espinal accesorio y disminución de fuerza masticadora en el caso de la rama motora del trigémino). En segundo lugar y como desventaja importante clásicamente descrita de estas transposiciones nerviosas encontramos la falta de movimientos faciales coordinados con la hemicara normal contralateral aunque se ha descrito una coordinación motora espontánea con buena adaptación cerebral (17).

Otro uso frecuente de la trasposición parcial de hipogloso se conoce como el principio "niñera" o "canguro" ("baby-sitter"), descrito por Julia Terzis, en el que se combinan las técnicas de transposición nerviosa con la de INFC (18). En un primer tiempo se realiza un INFC a las ramas cigomáticas del nervio facial sano y al mismo tiempo se traspone el extremo distal del nervio facial paralizado al hipogloso pero utilizando solamente un $30-40 \%$ del nervio donante, con lo que disminuye enormemente la morbilidad asociada a la transposición. En un segun- 

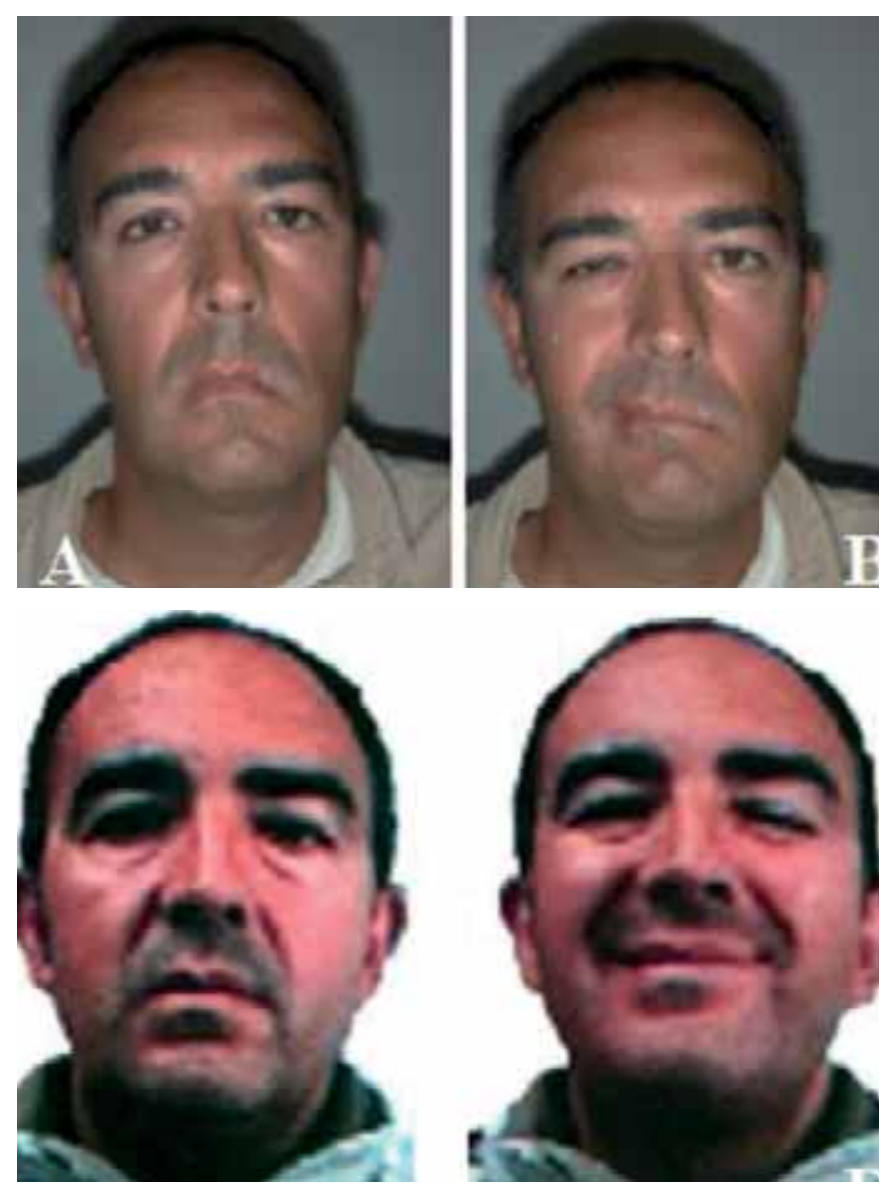

Fig. 5. Varón de 45 años intervenido de resección de neurinoma del acústico izquierdo 8 meses antes. C y D muestran al paciente dos años después de reconstrucción con injerto facial cruzado.

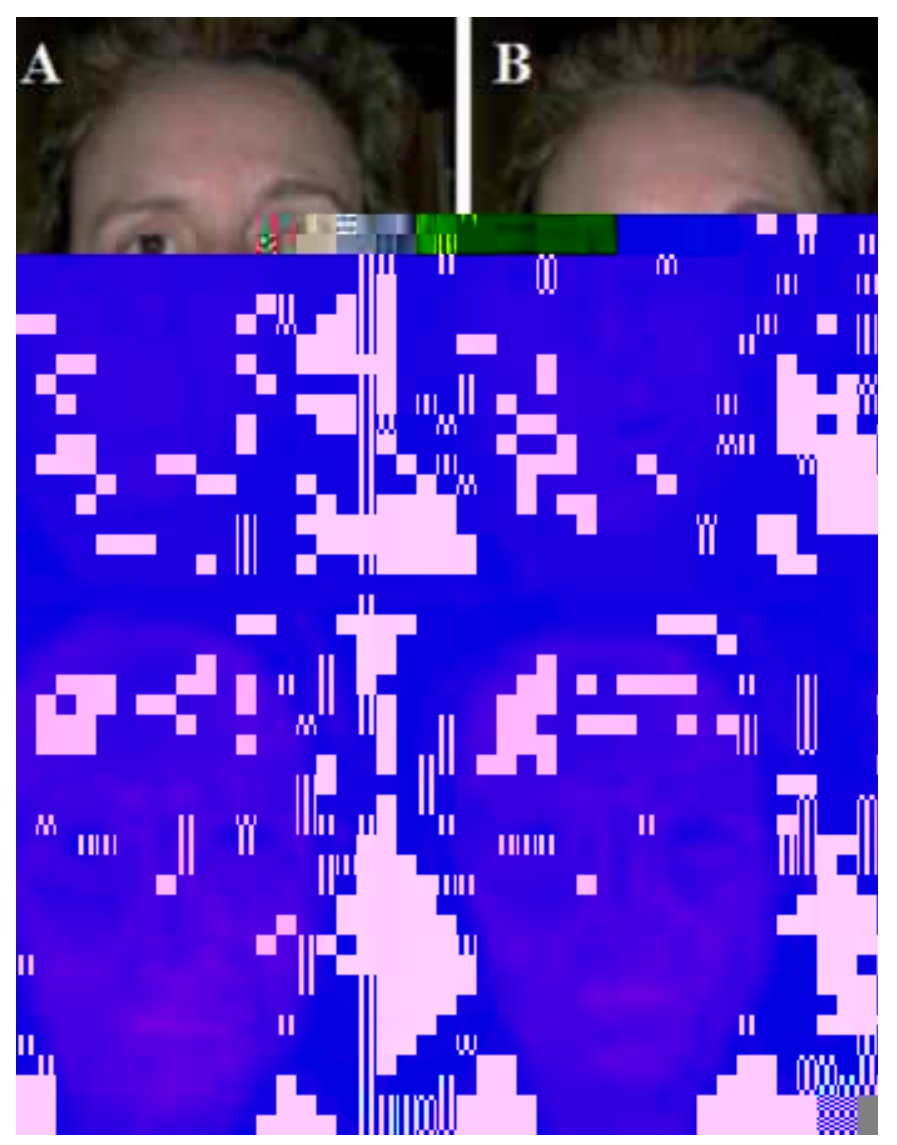

Fig. 6. Mujer de 42 años intervenida de resección de neurinoma del acústico derecho 32 meses antes. C y D muestran a la paciente dos años y medio después de reconstrucción con injerto facial cruzado. do tiempo, tras la regeneración nerviosa a través del INFC (unos 6-8 meses), se coaptan los extremos de éste a las ramas periféricas del nervio facial afecto sin seccionar la neurorrafia con el "canguro", que se mantiene para proporcionar fibras motoras adicionales. Mediante esta técnica se consigue por un lado detener el reloj de denervación manteniendo la masa muscular de la hemicara paralizada (gracias a la transposición nerviosa) y por otro lado se permite que el INFC actúe como "marcapasos" que posibilita el movimiento facial coordinado con el lado sano (Fig. 7 y 8 ).

\section{Transferencias musculares}

El nervio facial inerva 17 pares de músculos que interactúan entre sí para controlar la simetría facial, el tono y la expresión facial voluntaria e involuntaria (emocional). El adecuado funcionamiento de estos músculos se puede restaurar únicamente mediante las técnicas de neurorrafia descritas anteriormente. Desgraciadamente, en los pacientes cuya parálisis se instauró hace más de 3 años, sobre todo en mujeres jóvenes, éstas técnicas no suelen ser eficaces debido a la pérdida de placas motoras viables y a la fibrosis de los tubos neurales distales; es en estos casos donde resultan útiles las transferencias musculares locales o libres imitando en la medida de lo posible la acción del músculo zigomático mayor.

\section{Transferencias musculares locales}

La transferencia del músculo temporal es una técnica que clásicamente se ha utilizado para la rehabilitación de la sonrisa de forma dinámica y que hoy en día también se utiliza como segundo escalón quirúrgico en la rehabilitación del párpado paralizado (19). Sin embargo, su uso para la rehabilitación de la comisura bucal estaría indicado en las parálisis faciales bilaterales o en el Síndrome de Möebius, siguiendo la variación descrita por Labbé (20). En nuestra experiencia la utilización de la transferencia del músculo temporal es una buena opción en la rehabilitación de la sonrisa en pacientes varones mayores de 50 años y con piel gruesa. Por otro lado, la transposición del músculo masetero, hoy en día no debería utilizarse. Ninguno de los dos músculos puede restaurar de un modo completo el tono muscular facial ni tampoco producir movimiento facial emocional coordinado con el lado sano. Más aun, el entrenamiento y rehabilitación postoperatorios resultan cruciales para garantizar un éxito parcial de la intervención. La activación de estos músculos es muy limitada en comparación con la activación de los trasplantes musculares libres. De hecho, el arrastre de la comisura bucal en una transposición temporal no supera $1 \mathrm{~cm}$ siendo de 

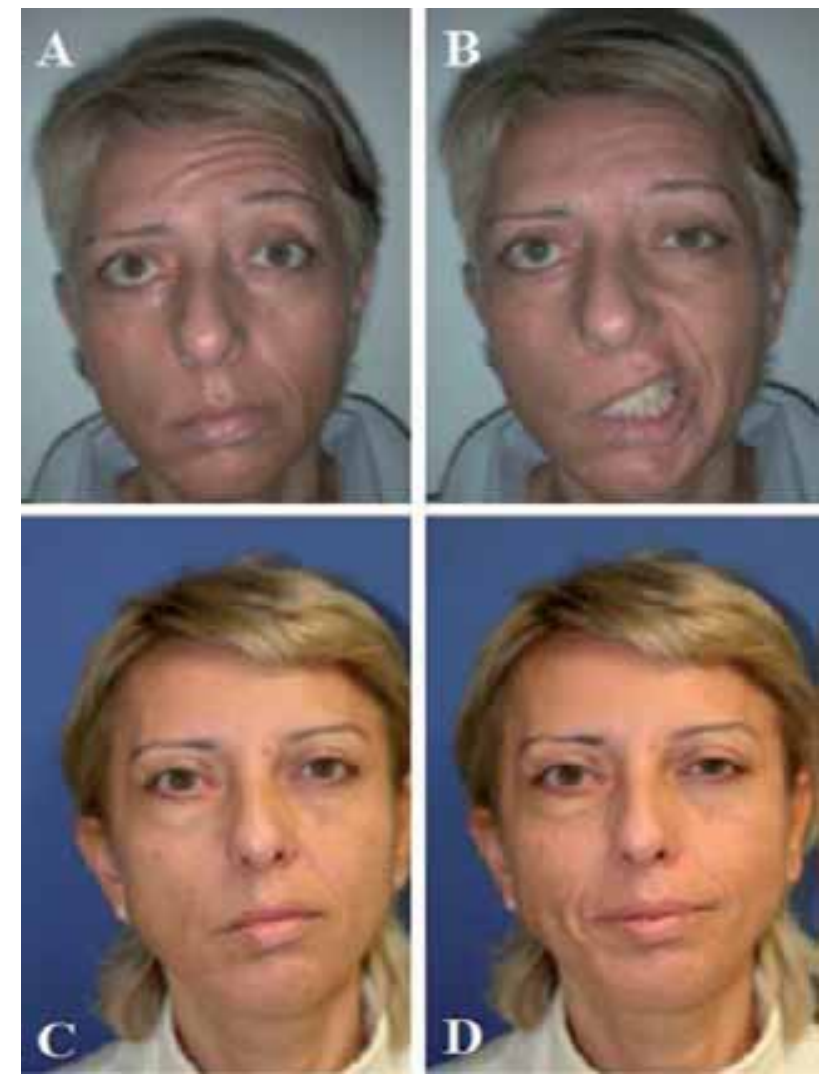

Fig. 7. Mujer de 47 años intervenida de resección de neurinoma del acústico derecho 13 meses antes. C y D muestran a la paciente dos años y medio después de reconstrucción con transposición hemihipogloso-facial con injerto.

hasta $2.5 \mathrm{~cm}$ cuando se utilizan los trasplantes musculares libres (Fig. 9).

\section{Trasplantes musculares microquirúrgicos}

La primera mioneurotización facial fue realizada por Lexer y Eden en 1911. Owens transpuso el músculo masetero para la reanimación facial en 1947 y en 1971 Thomson fue el primero en transplantar en la cara el músculo extensor breve de los dedos del pie y el músculo palmar mayor (21). Para su supervivencia, estos músculos dependían del crecimiento de los vasos circundantes presentes en el tejido adyacente. La neurotización del músculo transplantado tenía lugar a través del contacto directo con la musculatura facial inervada del lado normal o por medio de la sutura del nervio del músculo transplantado a una rama del nervio facial normal, concepto verdaderamente ingenioso. Sin embargo, muy pocos cirujanos eran capaces de obtener con estas técnicas una cantidad útil de movimiento de los músculos transplantados debido a una insuficiente reinervación de los mismos.

Con el desarrollo de la microcirugía vascular, es posible transplantar todo o parte de un músculo a la cara asegurando su supervivencia. Desde que este procedimiento fue descrito por Harii (22), el uso del trasplante muscular vascularizado se ha extendido
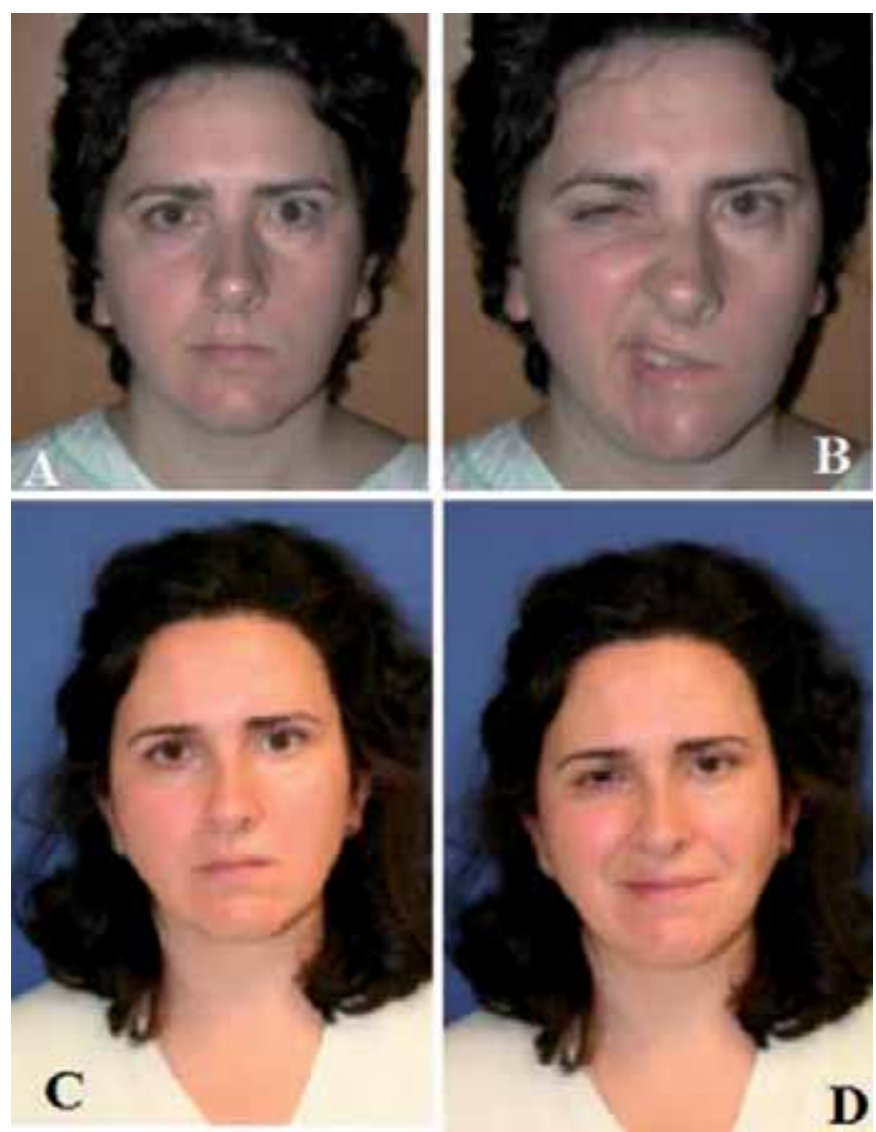

Fig. 8. Mujer de 26 años intervenida de resección de neurinoma del acústico izquierdo 19 meses antes. C y D muestran a la paciente dos años y medio después de reconstrucción con transposición hemihipogloso-facial con injerto.
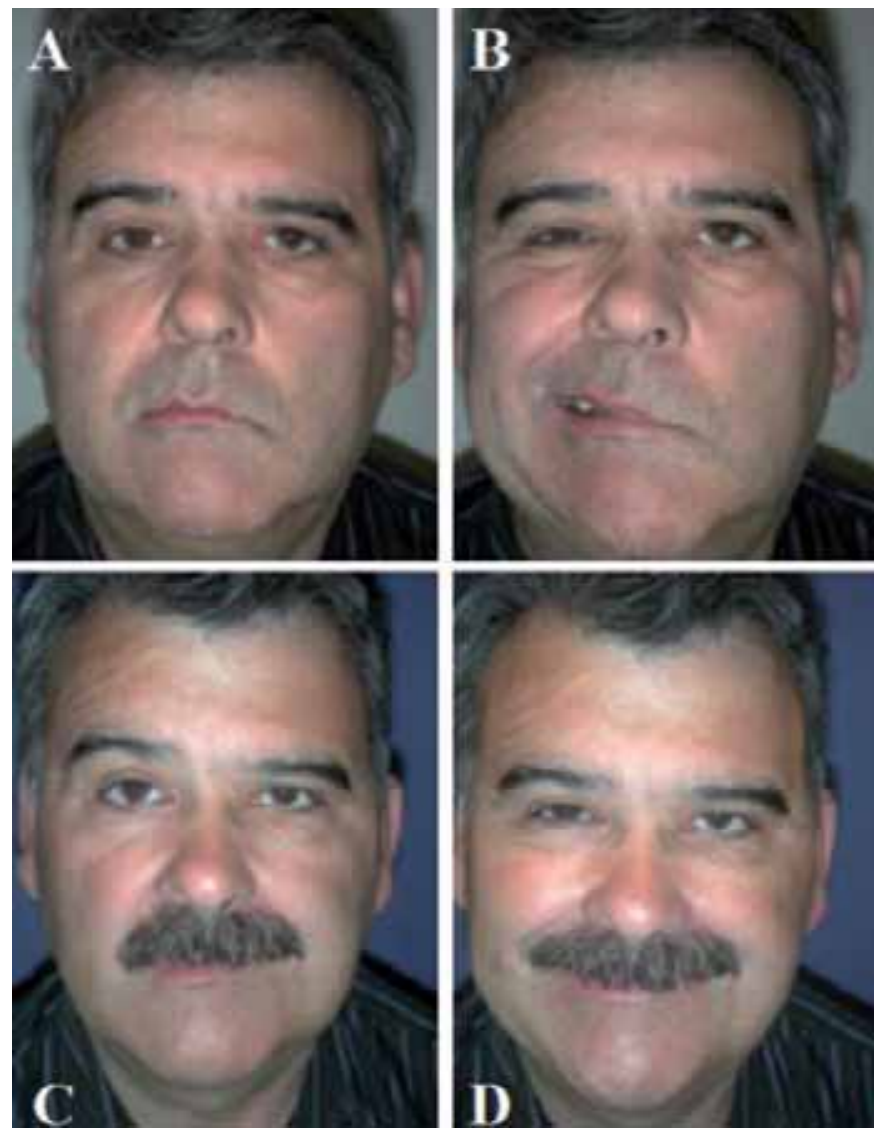

Fig. 9. Varón de 46 años intervenido de resección de neurinoma del acústico izquierdo 16 meses antes. C y D muestran al paciente dos años después de reconstrucción con transposición de músculo temporal (Técnica modifica de Labbé). 

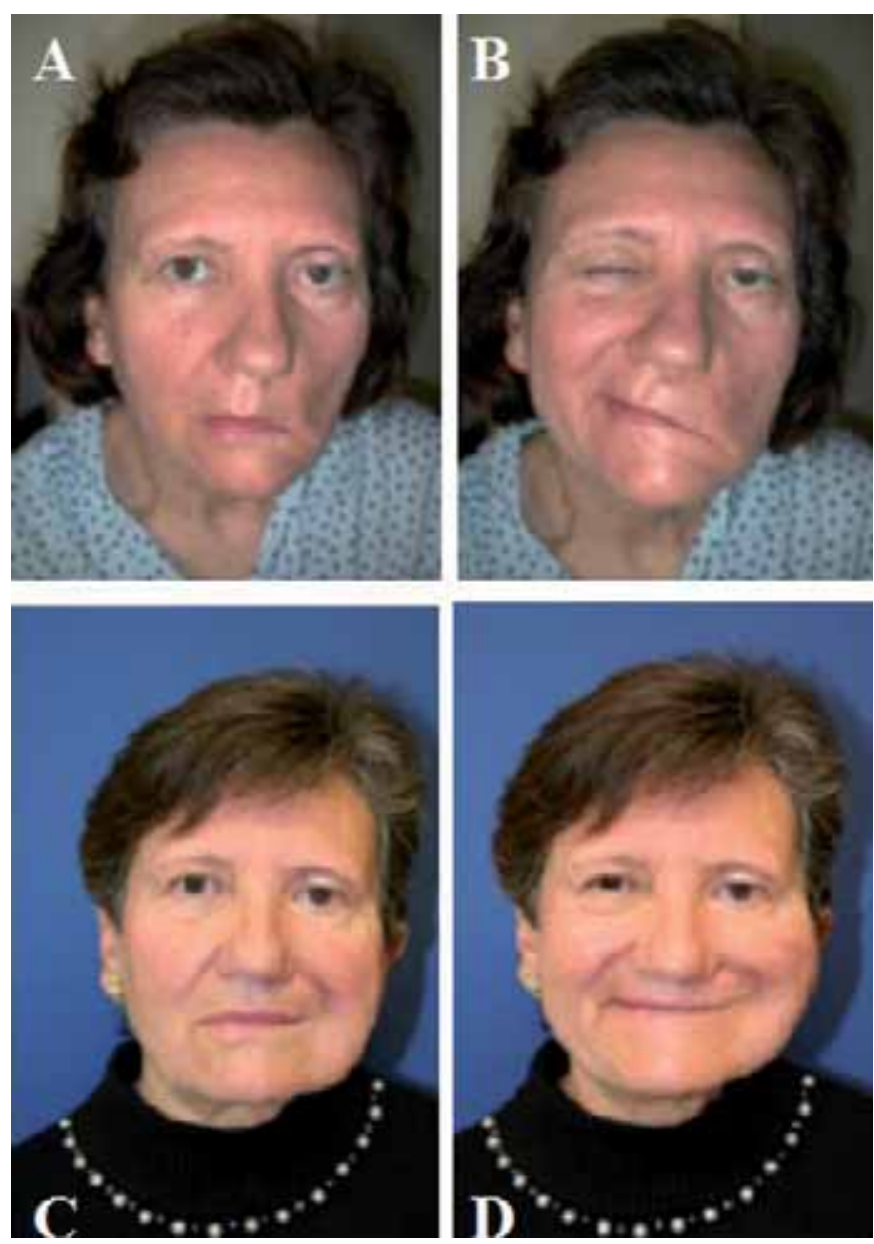

Fig. 10. Mujer de 55 años intervenida de resección de neurinoma de acústico izquierdo 6 años antes. C y D muestran a la paciente tres años y medio después de reconstrucción con injerto facial cruzado en un primer tiempo quiúrgico y transplante de músculo gracilis en un segundo tiempo.

ampliamente llegando a considerarse el tratamiento de elección en la rehabilitación de la sonrisa (23-25). En esta técnica, como ya se ha comentado previamente, son las ramas faciales seleccionadas del lado sano las que aportan el impulso nervioso necesario para la activación de la musculatura facial trasplantada.

Los músculos faciales trabajan en combinación unos con otros produciendo no sólo el tono facial y el movimiento voluntario, sino también la expresión facial involuntaria. Sin embargo, la habilidad del cirujano para transferir una o dos unidades musculares no permite, por mayor que sea la sofisticación para simular las contracciones de forma coordinada de los múltiples músculos, una expresión facial completamente natural. Así, el movimiento que muchos pacientes pueden conseguir es la elevación del ángulo de la boca simulando una sonrisa. El transplante muscular puede aportar este movimiento activo además de un balance simétrico de la boca en reposo. En cualquier caso, esta técnica de transplante muscular microquirúrgico produce una sonrisa mucho más natural que cualquier otro procedimiento.
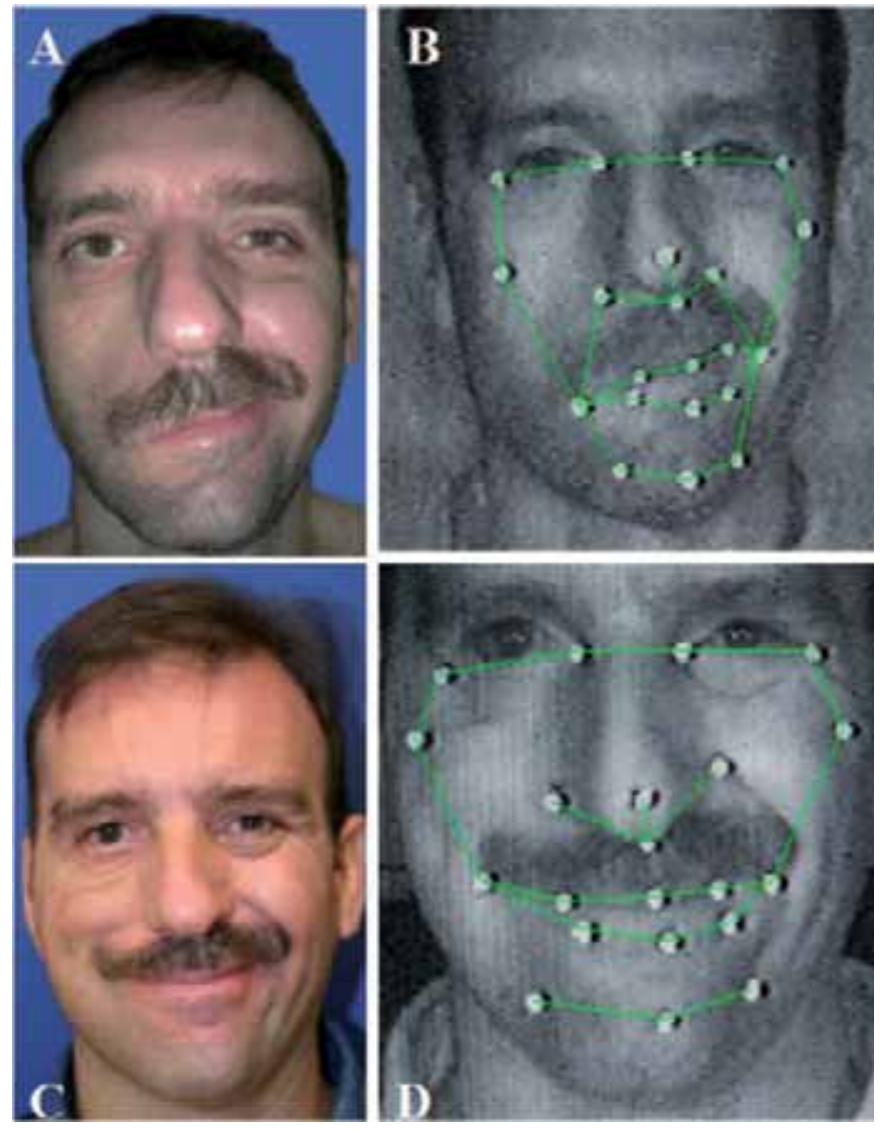

Fig. 11. Varón de 44 años intervenido de resección de neurinoma del acústico derecho 8 años antes. A y C muestran al paciente dos años después de reconstrucción con injerto facial cruzado en un primer tiempo quiúrgico y transplante de músculo gracilis en un segundo tiempo. B y D muestran el estudio mediante el captador facial diseñado en nuestro Departamento.

Cuando el músculo transferido es reinervado por el nervio facial, la sonrisa puede ser espontánea y no dependiente de movimientos voluntarios como la mordida o el movimiento de la lengua (procucidos por el nervio masetero e hipogloso, respectivamente). Además, la técnica de trasplante muscular permite al cirujano modelar la forma de la sonrisa observando el lado normal de la cara.

La transferencia microneurovascular de un músculo no es un procedimiento complicado; sin embargo, es relativamente complejo conseguir una buena demarcación del surco nasogeniano. La solución viene dada a la hora de escoger la cantidad de músculo necesaria para provocar la sonrisa, la selección de una buena inserción a nivel del surco, la aportación de una buena tensión al músculo y una buena reinervación del mismo (Fig. 10 y 11).

\section{-Selección del músculo:}

Los cirujanos plásticos hemos utilizado todas las áreas anatómicas de los músculos gracilis, dorsal ancho, serrato anterior, pectoral menor y del extensor corto de los dedos del pie para rehabilitar una cara 
paralizada. Sin embargo, no es tan importante el músculo que se elige sino la cantidad del mismo que se va a utilizar. El músculo seleccionado no debe producir ningún déficit funcional tras su extracción y debe estar distante de la cara, de tal manera que la preparación del mismo y de la cara puedan hacerse al mismo tiempo. El músculo pectoral menor, el serrato anterior y el gracilis cumplen esta condición.

El objetivo principal de un transplante muscular microvascularizado es elevar el ángulo de la boca para producir una sonrisa. Para ello se requiere de un músculo corto con una longitud funcional de 4-7 cm., una capacidad contráctil de 1-1,5 cm. y suficiente fuerza como para superar la gravedad y la resistencia de los tejidos. Debe tener además un pedículo vascular y una anatomía nerviosa constantes para permitir una transferencia microvascular. Los músculos largos como el gracilis (26), dorsal ancho o serrato anterior son los idóneos para obtener una porción de músculo de suficiente tamaño y capacidad funcional. La cantidad de músculo transferido varía entre los individuos y por tanto en cada reconstrucción. Un paciente con una sonrisa poderosa en el lado normal de la cara y con tejidos faciales duros y compactos, podría requerir un músculo de mayor tamaño que un paciente con una sonrisa débil y tejidos faciales blandos. Más aun, cuando se utiliza un injerto cruzado del nervio facial sano se debe utilizar una mayor porción de músculo, ya que el injerto no tiene la misma capacidad de inervación que una reparación nerviosa directa (Fig. 12).

\section{- Inervación muscular:}

La neurotización muscular puede alcanzarse utilizando el nervio facial del lado de la parálisis o el nervio facial del lado normal, o incluso de otros nervios motores que están en la vecindad, como son el nervio hipogloso o las ramas motoras del nervio trigémino. La neurotización con el nervio facial es la ruta preferida, ya que tiene el impulso nervioso que es el normalmente producido en el mismo momento de la expresión facial. Probablemente la única manera de obtener un movimiento facial involuntario y una expresión facial espontánea sea utilizando el propio nervio facial, aunque se ha observado un movimiento facial espontáneo con la utilización del nervio maseterino (27).

La selección de una rama bucal puede proporcionar axones a muchos músculos individuales, incluyendo el orbicular de los labios y el cigomático mayor que tienen acciones diferentes y conflictivas entre sí. Por tanto, si la rama nerviosa seleccionada es la que proporciona acción al músculo orbicular de los labios como principal actividad, el transplante muscular recibirá un impulso nervioso sólo cuando el paciente intente protuir los

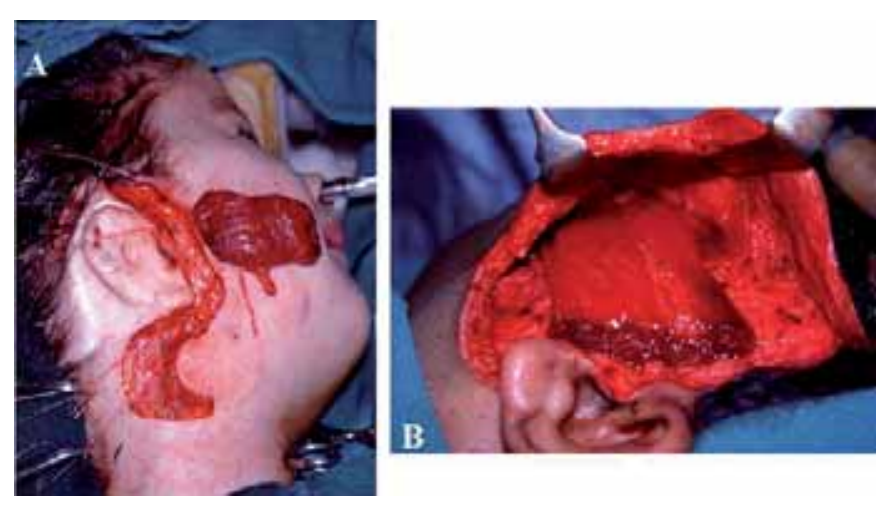

Fig. 12. A muestra un detalle quirúrgico de la interposición de un segmento del músculo gracilis. B se observa el músculo interpuesto una vez terminadas las microanastomosis vasculares a los vasos faciales.

labios. Más aún, si se utiliza el cabo proximal del nervio hay dos posibilidades de que el músculo trasplantado pueda tener movimiento, al activar el músculo orbicular de los labios o el orbicular de los párpados. Así, la neurotización selectiva apropiada para el músculo trasplantado puede dificultarse cuando se utilizan los cabos nerviosos del nervio facial del lado paralizado. Si no existen buenos cabos nerviosos disponibles en el lado paralizado, la fuente preferente de neurotización será el nervio facial opuesto. Esta situación es la óptima en el paciente que tiene una lesión del nervio facial a nivel intracraneal tras un trauma, resección de un neuroma del acústico o de una parálisis de Bell. La excitación nerviosa se transporta por un injerto nervioso largo situado en la cara desde el lado normal al lado paralizado. Este nervio facial cruzado debe ser observado durante aproximadamente 6 meses antes del transplante muscular, a la espera de su neurotización.

En la técnica de injerto facial cruzado (17), dividimos algunas de las ramas del nervio facial del lado normal y las suturamos al cabo proximal del injerto nervioso. El injerto se interpone a lo largo de la cara por medio de un túnel subcutáneo hacia el lado paralizado y el cabo distal del injerto se deposita a nivel de la cara profunda del labio superior del lado paralizado. Si se esperan entre 6 y 8 meses antes del transplante muscular, los axones en regeneración alcanzarán el cabo distal del injerto nervioso y estarán disponibles para una reinervación inmediata del músculo transplantado. Anticipándose a cualquier atrofia del músculo transplantado el cirujano puede transplantar una gran porción de músculo.

El procedimiento de injerto facial cruzado se puede realizar sin provocar ninguna lesión en el nervio facial sano debido a las múltiples anastomosis existentes entre las ramas que entrelazan sus funciones. Aproximadamente el $50 \%$ de las ramas a nivel del borde medial de la parótida pueden dividirse y ser donadas para la inervación de un injerto facial cruzado sin ninguna perdida funcional aparente del lado sano. Tras la 

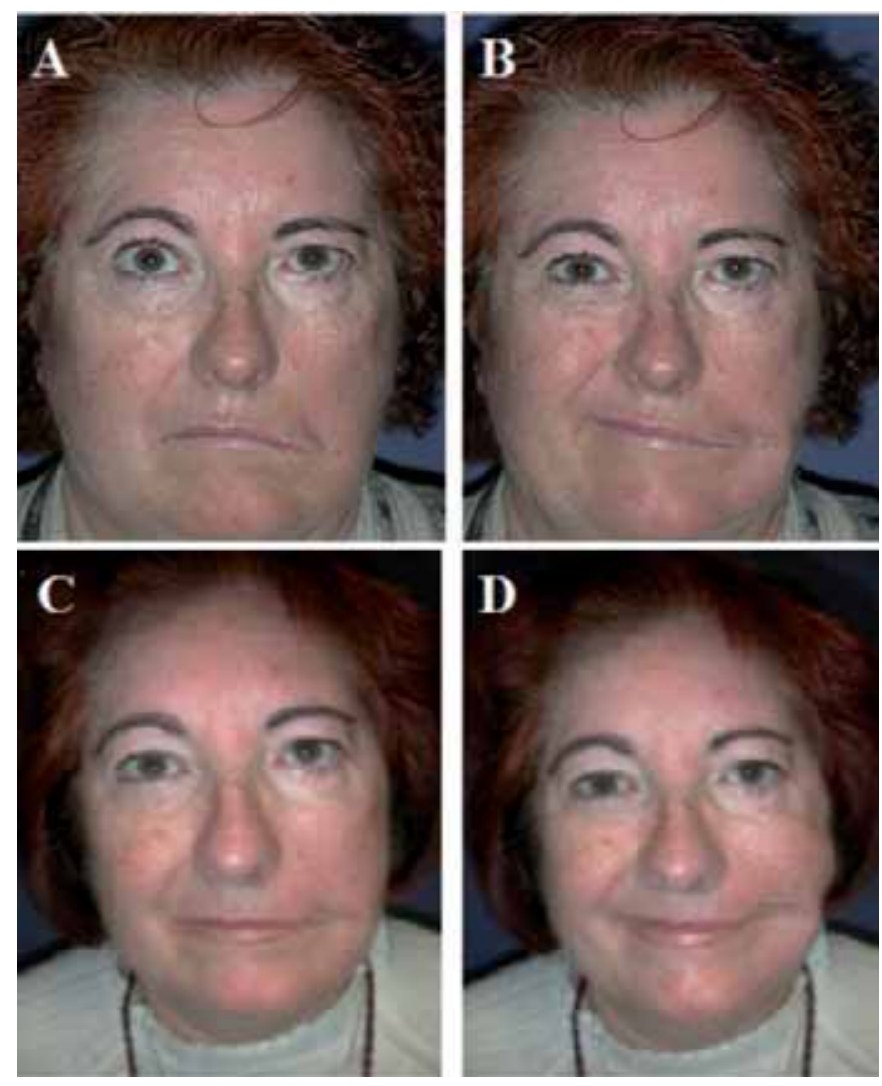

Fig. 13. Mujer de 56 años intervenida de resección de neurinoma del acústico izquierdo 12 años antes y multioperada con varios procedimientos que fracasaron para mejoría del movimiento facial. C y D muestran a la paciente tres años y medio después de reconstrucción con transplante muscular en un tiempo quirúrgico utilizando un segmento de músculo dorsal ancho.

reinervación del injerto, el paciente notará una sensación de calambre cuando se percuta sobre el cabo distal del injerto nervioso. Es interesante que este signo de Tinnel se localice a nivel de las ramas donantes del injerto facial. Cuando se percute el cabo distal del injerto nervioso se produce una sensación de calambre que indica que la regeneración nerviosa ha tenido lugar adecuadamente y por tanto que el transplante muscular puede ser realizado.

En casos especiales (pacientes multioperados y menores de 50 años) se puede realizar un trasplante muscular libre utilizando el músculo dorsal ancho en un solo tiempo quirúrgico (28) (Fig. 13).

\section{PARALISIS FACIAL BILATERAL Y SINDROME DE MÖEBIUS}

El síndrome de Möebius es un trastorno del desarrollo que se caracteriza por una parálisis facial bilateral. Suelen estar afectados el VI y VII pares craneales. También puede afectar al III, V, IX y XII pares craneales. Se asocia a malformaciones en las extremidades en 1 de cada 4 casos y en un $15 \%$ existen alteraciones en la musculatura pectoral. Raramente la parálisis es unilateral, pero estos pacientes siempre tienen una afectación de algún par craneal contralateral.
Cuando existe una parálisis facial bilateral no existe como fuente donante el VII par craneal. En estos pacientes hemos utilizado las ramas motoras del nervio trigémino como nervio donante. Este nervio es fácilmente identificable en la superficie profunda del masetero donde aparece debajo del arco cigomático. La desventaja de utilizar este nervio es que los impulsos nerviosos para el movimiento de la expresión facial no producen un movimiento natural. Sin embargo, con entrenamiento, estos pacientes pueden desarrollar la habilidad para crear una sonrisa de manera consciente. En nuestras manos este transplante muscular proporciona una sonrisa natural fuerte, mejor que la transferencia del músculo temporal y que las transferencias locales del músculo masetero.

El objetivo del tratamiento quirúrgico es conseguir unos pliegues nasolabiales simétricos y funcionantes que puedan imitar a los que se producen durante la sonrisa. Esta intervención se realiza en dos tiempos quirúrgicos utilizando la rama motora del nervio trigémino (un tiempo para cada músculo). En el mismo momento se realiza una transposición muscular libre (generalmente con el músculo gracilis), repitiendo dichos procedimientos para el lado contralateral. El nervio facial contralateral y el nervio hipogloso ipsilateral normalmente no se pueden utilizar ya que suelen estar ausentes o no ser funcionantes.

\section{Suspensión estática facial}

Si bien los procedimientos quirúrgicos dinámicos procuran restaurar el tono y la función faciales normales, existen otros procesos denominados estáticos que permiten mejorar la simetría facial en reposo, pudiendo cambiar ostensiblemente la apariencia facial global. Se suelen realizar tanto en los pacientes que no son candidatos a las técnicas dinámicas por su edad (mayores de 65 años), como en aquellos, que por su estado general no tolerarían una intervención prolongada. En numerosas ocasiones estos procedimientos se suelen combinar con los procedimientos dinámicos para afinar el resultado.

Entre estas técnicas se incluyen el lifting frontal y facial asimétrico, el aumento malar, las tiras de tracción estáticas (injertos tendinosos, fascia lata autóloga o liofilizada...). También se pueden realizar neurectomías, miotomías o aplicar toxina botulínica tanto en el lado enfermo cuando se hayan producido sincinesias (reinervación facial aberrante), como en el lado sano para disminuir la acción muscular sana y conseguir así una mayor simetría. Nosotros habitualmente realizamos la suspensión por medio de injertos tendinosos del tendón de delgado plantar. Realizando dos vueltas con el tendón a través del arco cigomático y de tres puntos de anclaje a nivel del modiolus y $1 \mathrm{~cm}$. 

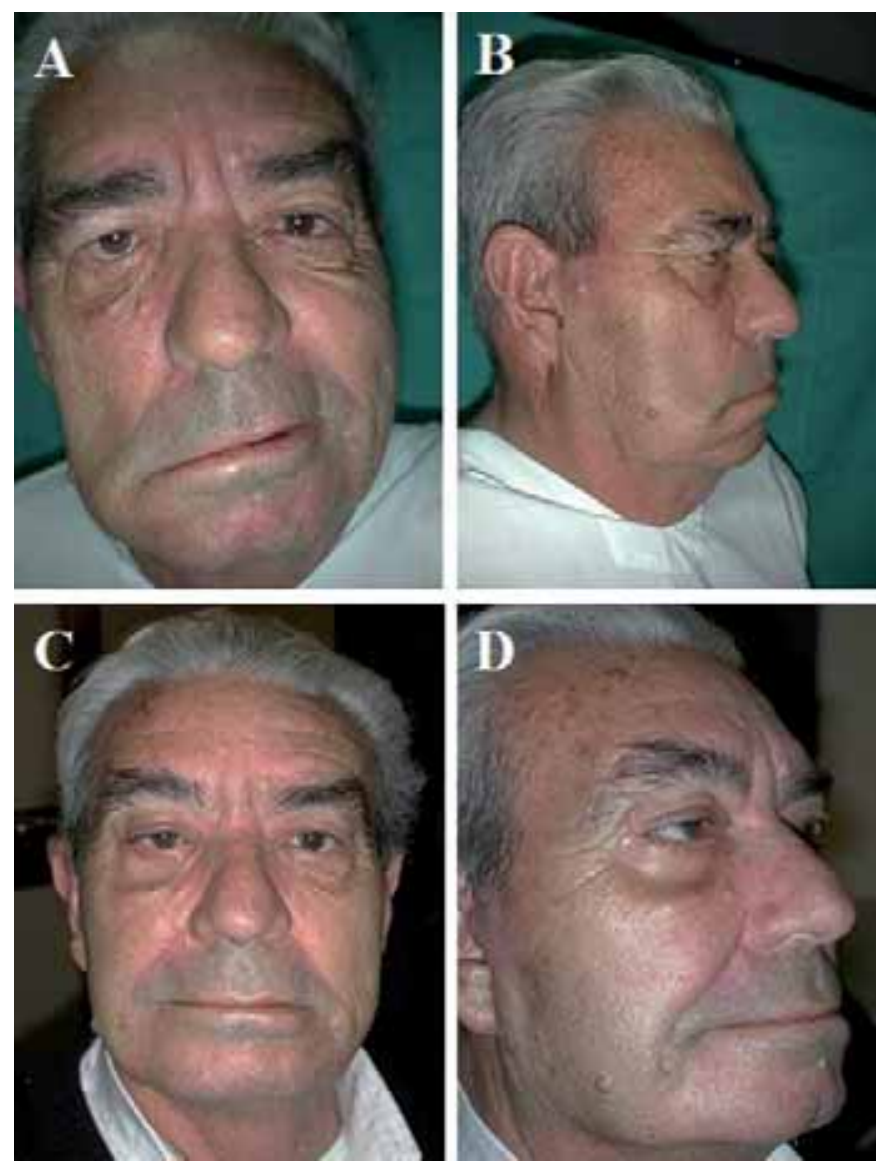

Fig. 14. Varón de 83 años intervenido de resección de neurinoma del acústico derecho 12 años antes. C y D muestran al paciente tres años y medio después de reconstrucción con interposición de tendón de músculo delgado plantar con anclaje en el arco cigomático. También se procedió a la interposición de una pesa de oro y de un tendón en el párpado inferior.

por encima y por debajo de este, se procede a realizar la hipercorrección, sabiendo que en el transcurso de 3 meses ira relajándose de forma parcial. En general evitamos utilizar cualquier material no antólogo para la suspensión. Con estas técnicas conseguimos no sólo una mejoría estética de la cara sino que obtenemos una mejoría del habla, de la respiración nasal por expansión de las alas nasales y evitamos mordidas involuntarias de la mucosa bucal al comer (Fig. 14).

A modo de resumen queremos representar por medio de un algoritmo (Esquema 1) el tratamiento estático y dinámico anteriormente expuesto.

\section{REHABILITACION OCULAR EN LA PARALISIS FACIAL}

Las alteraciones que aparecen tanto en el párpado superior como en el inferior tras la lesión del nervio facial están bien establecidas. El lagoftalmos es el trastorno más frecuente en el párpado paralítico. Este fenómeno suele ser la causa de sequedad ocular y de úlceras corneales. Otra alteración frecuentemente asociada es la ptosis palpebral y, en su grado máximo, el ectropion. Ambas provocan una dificultad en la correcta aposición del punto lacrimal inferior al globo ocular, que dificulta el drenaje de la lágrima y favorece la epífora. Sin embargo, en ocasiones, ésta puede ser secundaria a hipersecreción lacrimal refleja debida a exposición corneal por lagoftalmos. También puede ser secundaria a inervación aberrante de la glándula lacrimal por el nervio facial, fenómeno que aparece durante los primeros meses tras la lesión del nervio facial ("lágrimas de cocodrilo"), en las parálisis faciales temporales. En los pacientes afectos de parálisis facial peri-

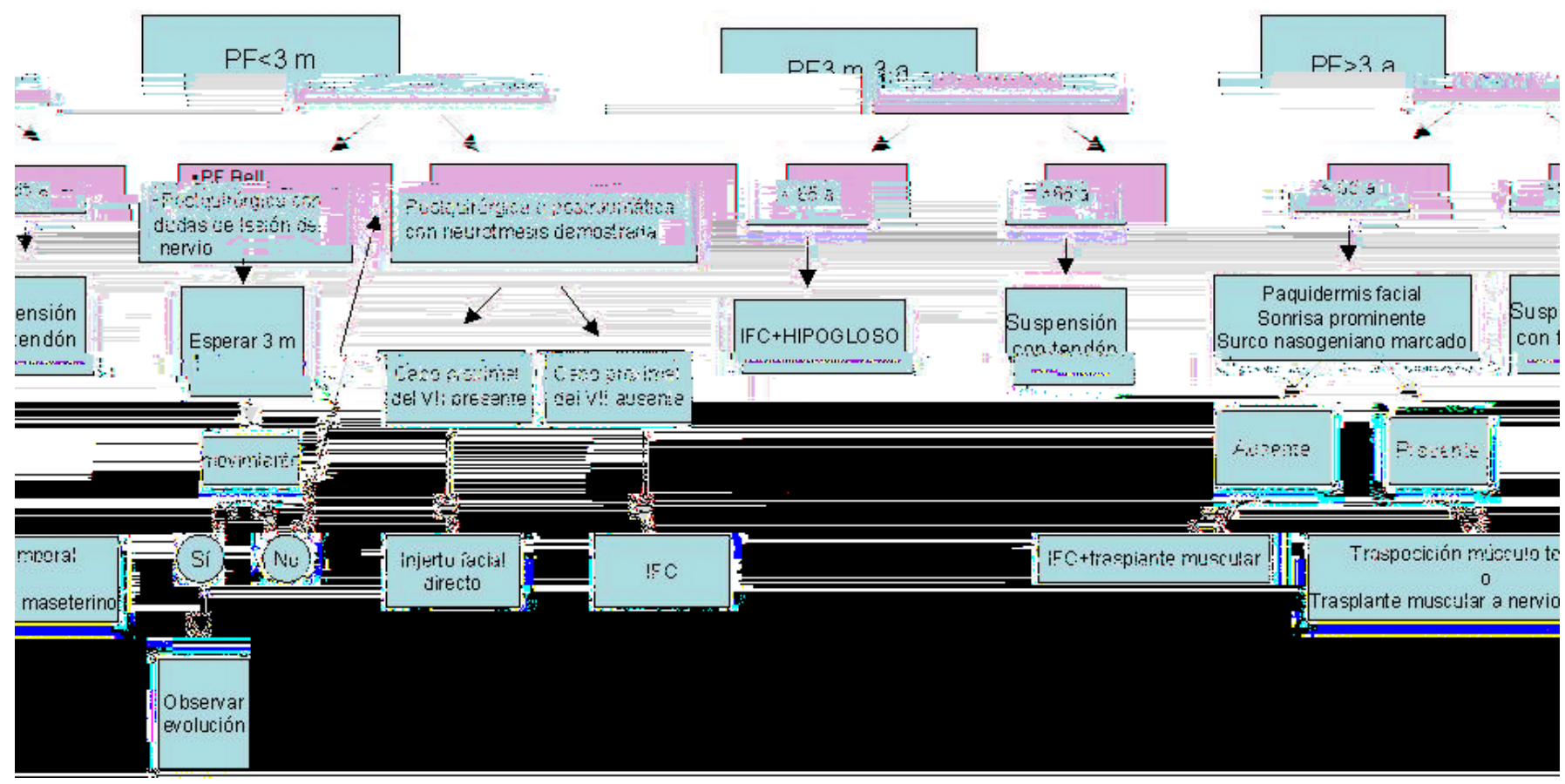

Esquema 1. Algoritmo del protocolo quirúrgico de reconstrucción estática y dinámica de la sonrisa en la parálisis facial que realizamos en nuestro centro. (PF. Parálisis facial. IFC. Injerto facial cruzado). 

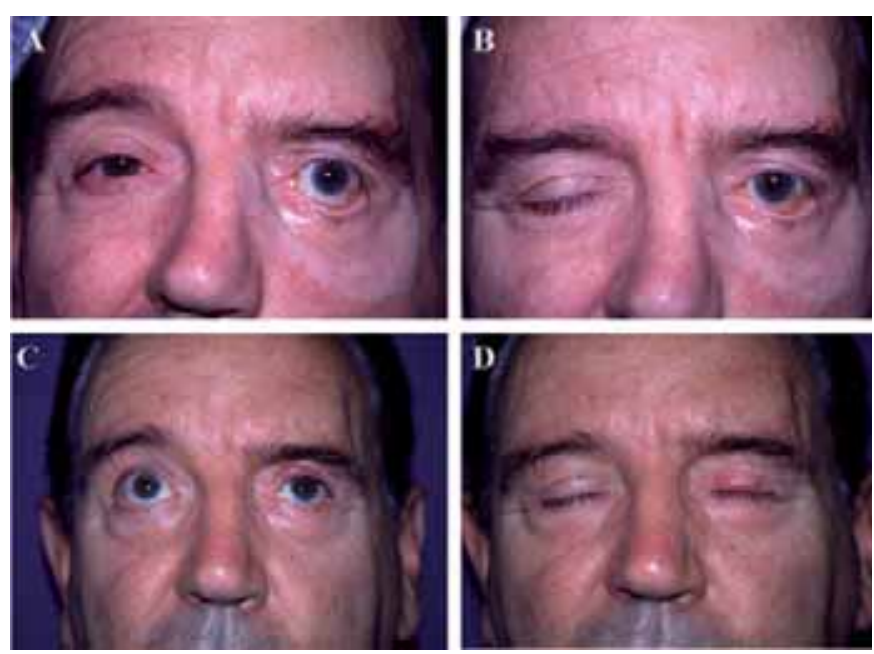

Fig. 15. Varón de 63 años que presentó lafoftalmos, epífora, ptosis de la ceja y ectropion tras parálisis facial idiopática izquierda (A y B). Se procedió a la interposición de un tendón en párpado inferior, pesa de oro de 1.2 grs en párpado superior y escisión elíptica fromtal. Resultados al año de la cirugía (C y D).

férica, es habitual observar ptosis de la ceja, sobre todo en personas seniles y en ocasiones, luxación de las tres bolsas grasas de los párpados inferiores. Este último fenómeno se debe a la parálisis del músculo orbicular que no puede contener la presión que ejercen estas bolsas hacia el exterior. Esta luxación de las bolsas grasas en el párpado paralítico se hace más prominente en pacientes con laxitud de piel.

\section{Corrección del párpado superior}

Aunque se han descrito numerosas técnicas para la corrección del lagoftalmos, empleamos la implantación de una prótesis palpebral de oro en el párpado superior, que se coloca a $5 \mathrm{~mm}$. del borde libre realizando una incisión en el pliegue palpebral superior a través de la piel y del músculo orbicular, hasta exponer el plano tarsal. La prótesis se fija en la mitad superior del tarso, de manera que al elevar el párpado es posible esconder el abultamiento que produce. El cálculo del peso final de la prótesis, para provocar el cierre completo de párpado, se determina por la variación de los ángulos entre los planos cutáneos y pretarsal. Esta variación determina la adición de 0.2 grs. a la pesa de prueba que se realizó en consulta (29). Sin embargo, hay que tener en cuenta que el cierre ocular puede estar parcialmente favorecido, tanto por el exceso cutáneo del párpado superior como por el peso que ejerce la ceja ptósica al caer sobre el párpado. Así, hay que tener especial cuidado a la hora de calcular el peso definitivo si se va a llevar a cabo de forma adicional una blefaroplastia superior en el párpado paralizado, o una corrección de la ceja ptósica.

Para la corrección de la ptosis de la ceja, se ha utilizado la escisión elíptica frontal descrita por Passot con sus posteriores modificaciones; consiste en una incisión horizontal justo en el límite superior de la ceja, disecando en sentido craneal, en el plano subcutáneo y resecando el exceso de tejido. Siempre hay que hipercorregir la elevación de la ceja, puesto que con el transcurso de los meses tiende a descender. Si existe un exceso cutáneo en el párpado superior realizamos una blefaroplastia superior, uni o bilateral, para obtener un mejor resultado estético (Fig. 15).

\section{Corrección del párpado inferior}

La interposición de una cincha tendinosa es la técnica de elección para corregir tanto la ptosis como el ectropion del párpado inferior. Se trata de una técnica de reconstrucción estática que sostiene el párpado inferior, de modo que el margen palpebral quede correctamente aposicionado sobre el globo ocular y a $1 \mathrm{~mm}$. del borde inferior pupilar. El tendón procede del músculo palmar largo cuando sólo se lleva a cabo la corrección palpebral de la parálisis facial, o bien del músculo delgado plantar, cuando además se asocia a una suspensión estática a nivel facial (18).

Cuando existe una epífora, se realiza una cantopexia interna, consistente en, una vez localizado el ligamento cantal interno unido a la cincha tendinosa, fijarlo con puntos de ethilon $4 / 0$ al periostio de los huesos propios nasales en dirección ascendente, asegurándonos de la correcta aposición del punto lagrimal al globo ocular.

En otras ocasiones, en pacientes con piel gruesa o paquidérmica y fundamentalmente para reforzar la cincha tendinosa, realizamos una cantoplastia externa que se lleva a cabo por medio de una incisión cutánea en la región cantal externa. A continuación, se procede a la cantolisis del ligamento cantal y se fija éste al periostio del reborde orbitario supero-lateral con Ethilon ${ }^{\circledR}$ de 5/0. En muy raras ocasiones la hacemos de forma aislada en un párpado paralítico, aunque esta técnica tiene sus indicaciones precisas en la cirugía de blefaroplastia. La resección en cuña se lleva a cabo siempre asociada a la interposición de la cincha tendinosa. Esta resección pentagonal del párpado inferior, se realiza cuando existe una laxitud cutánea importante asociada al ectropion y que provoca un descolgamiento importante del párpado inferior (18) (Fig. 16).

Finalmente, para corregir la luxación de las bolsas grasas palpebrales inferiores frecuentemente asociada al párpado paralítico, solemos realizar una blefaroplastia. Sin embargo, hemos observado que cuando se lleva a cabo una suspensión estática del tercio superior del surco nasogeniano por medio de una cincha tendinosa, el arrastre que se produce de todo el párpado inferior en dirección ascendente es suficiente para resolver este problema. 

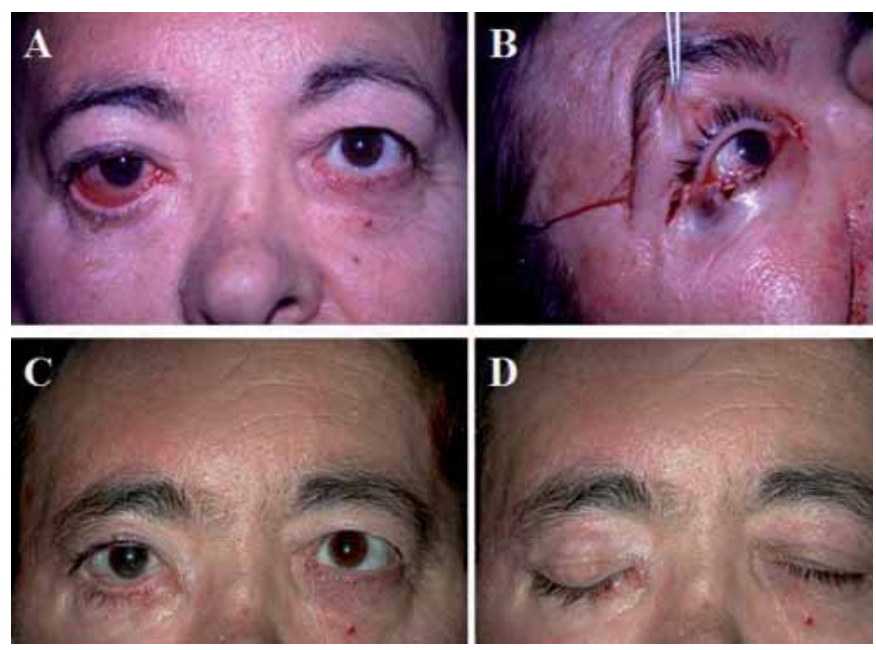

Fig. 16. Mujer de 57 años que sufrío parálisis facial por infarto cerebral. Presentó ectropion importante y lagoftalmos (A y B). Tratada mediante interposición de tendón de palmar largo y pesa de oro. Resultado a los dos años (C y D).

Cuando se utiliza la transposición del músculo temporal, el reflejo trigémino facial se pierde puesto que para cerrar el párpado es necesario apretar los dientes de forma voluntaria. Es verdad que el cierre palpebral que se consigue con la transposición del músculo temporal es dinámico, tanto del párpado superior como del inferior, pero no es un movimiento fisiológico. Por lo tanto, una técnica dinámica frente a una estática no parece que ofrezca mayores ventajas, siendo esta última más agresiva. La transposición del músculo temporal es una buena opción cuando no son eficaces la pesas de oro, pues en el $10 \%$ de los casos, éstas no proporcionan un cierre palpebral adecuado o se extruyen.

\section{Conclusiones}

El método a elegir para la rehabilitación de la parálisis facial en un paciente depende de múltiples factores como son la edad, el sexo, el tipo de piel facial, los procedimientos previos realizados y las preocupaciones del propio paciente. Gracias a un método de cuantificación tridimensional del movimiento facial hemos podido, siguiendo nuestra casuística, realizar un algoritmo lógico para determinar tanto el momento como el tipo de reconstrucción a realizar para la reconstrucción de la sonrisa. En cuanto a la reconstrucción ocular, el manejo de las alteraciones que se producen en el párpado paralítico tras una parálisis facial tiene que ser lógico, puesto que hemos de utilizar técnicas quirúrgicas cuyo resultado asemeje la función fisiológica del párpado normal.

\section{Agradecimientos}

Queremos mostrar nuestro profundo agradecimiento al Dr. Ángel Vidal Santana por los comentarios, sugerencias e indicaciones para la elaboración de este trabajo.

\section{Dirección del autor}

\section{Dr. Bernardo Hontanilla Calatayud}

Departamento de Cirugía Plástica, Estética y Reparadora

Clínica Universitaria. Universidad de Navarra

C/ Pío XII, 36. 31008 Pamplona. Navarra. España. e-mail: bhontanill@unav.es

\section{Bibliografía}

1. Adour KK, Swanson PJ Jr.: "Facial paralysis in 403 consecutive patients: emphasis on treatment response in patients with Bell's palsy." Trans Am Acad Ophthalmol Otolaryngol 1971; 75: 1284.

2. House JW, Brackmann DE.: "Facial nerve grading system." Otolaryngol Head Neck Surg 1985; 93: 146.

3. Ross BG, Fradet G, Nedzelski JM.: "Development of a sensitive clinical facial grading system." Otolaryngol Head Neck Surg 1996; 114: 380 .

4. Coulson SE, Croxon GR, Adams RD, O'Dweyer NJ.: "Reliability of the "Sidney", "Sunnybrook", and "House Brackman" facial grading systems to assess voluntary movement and synkinesis after facial nerve paralysis." Otolaryngol Head and Neck Surg 2005; 132:543.

5. Coulson SE, Croxson G R, Gilleard WL.: "Three-dimensional quantification of points during normal facial movement." Ann Otol Rhinol Laryngol 1999; 108: 265.

6. Frey M, Jenny A, Giovanoli P, Stussi E.: "Development of a new documentation system for facial movements as a basis for the international registry for neuromuscular reconstruction in the face." Plast Reconstr Surg 1994; 93: 1334.

7. Isono M, Murata K, Tanaka H, Kawamoto M, Azuma H.: "An objective evaluation method for facial mimic motion." Otolaryngol Head Neck Surg 1996; 114: 27.

8. Johnson PC, Brown H, Kuzon WM, Balliet R, Garrison JL, Campbell J.: "Simultaneous quantitation of facial movements: The maximal static response assay of facial nerve function." Ann Plast Surg 1994; 32: 171 .

9. Linstrom C J, Silverman CA, Susman WM.: "Facial-motion analysis with a video and computer system: A preliminary report." Am J Otol 2000; 21: 123

10. Wachsman GS, Cohn JF, VanSwearingen JM, Manders EM.: "Automated tracking of facial features in patients with facial neuromuscular dysfunction.” Plast Reconstr Surg 2001; 107: 1124.

11. Sargent EW, Fadhli OA, Cohen RS.: "Measurement of facial movement with computer software." Arch Otolaryngol Head Neck Surg 1998; 124: 313.

12. Neely JG, Cheung JY, Wood M, Byers J, Rogerson A.: “Computerized quantitative dynamic analysis of facial motion in the paralyzed and synkinetic face." Am J Otol 1992; 13: 97-107.

13. Meier-Gallati V, Scriba H, Fisch U.: "Objective scaling of facial nerve function based on area analysis (OSCAR)." Otolaryngol Head Neck Surg 1998; 118: 545.

14. Yuen K, Kawakami S, Ogawara T, Inokuchi I, Maeta M, Masuda Y.: "Evaluation of facial palsy by Moire topography." Eur Arch Otorhinolaryngol Suppl S 1994; 541.

15. Tomat LR, Manktelow RT.: "Evaluation of a new measurement tool for facial paralysis reconstruction." Plast Reconstr Surg 2005; 115: 696.

16. Hontanilla B, Auba C.: "Automatic three-dimensional quantitative analysis for evaluation of facial movement." J Plast Reconstr Aesthet Surg 2007; 12 :

17. Anderl F.: "Reconstruction of face through cross-face nerve trasplantation in facial paralysis." Chirugia plastica 1973; 2: 17.

18. Mersa B., Tiangco D.A., Terzis J.K.: "Efficacy of the "baby-sitter" procedure after prolonged denervation." J Reconstr Microsurg 2000; 16: 27.

19. Hontanilla B., Aubá C.: "Corrección quirúrgica del párpado paralizado en la parálisis facial” Cir. plást. iberolatinoam. 2004; 30(4): 275. 
20. Labbe D., Huault M.: "Lengthening temporalis myoplasty and lip reanimation." Plast Reconstr Surg 2000;105: 1289.

21. Thompson N.: "Autogenous free grafts of skeletal muscle. A preliminary experimental and clinical study." Plast Reconstr Surg 1971; 48: 11 .

22. Harii K., Ohmori K., Tori S.: "Free gracilis muscle transplantation, with microneurovascular anastomoses for the treatment of facial paralysis. A preliminary report”. Plast Reconstr Surg 1976; 57: 133.

23. Manktelow R.T.: "Microvascular reconstruction." New York, Springer-Verlag, 1986.

24. O'Brien B.M., Franklin J.D., Morrison W.A.: "Cross-facial nerve grafts and microneurovascular free transfer for long stablished facial palsy.” Br J Plast Surg 1980; 33: 202.
25. Tolhurst D.E., Bos K.E.: "Free revascularized muscle grafts in facial palsy." Plast Reconstr Surg 1982; 69: 760.

26. Manktelow R.T., Zuker R.M.: "Muscle transplantation by fascicular territory." Plast Reconstr Surg 1984, 73: 751.

27. Manktelow RT, Tomat LR, Zuker RM, Chang M.: "Smile reconstruction in adults with free muscle transfer innervated by the masseter motor nerve: effectiveness and cerebral adaptation." Plast Reconstr Surg. 2006 15;118(4):885.

28. Harii K., Asato H., Yoshimura K., Sugawara Y., Nakatsuka T., Ueda K.: "One-stage transfer of the latissimus dorsi muscle for reanimation of a paralyzed face: a new alternative." Plast Reconstr Surg 1998;102: 941.

29. Hontanilla B.: "Weight measurement of upper eyelid gold implants for lagophthalmos in facial paralysis." Plastic Reconst Surg 2001; 108:1539. 


\section{Comentario al trabajo uProtocolo quirúrgico en la reconstrucción de la parálisis facial: nuestra experiencia tras 140 casos tratados"}

\section{Dr. Enrique Pérez Luengo Cirujano Plástico. Práctica privada. Madrid. España.}

El Dr. Hontanilla y sus colaboradores presentan un trabajo con dos aportaciones importantes al tratamiento de la parálisis facial definitiva: por un lado, una herramienta para la valoración de resultados, basada en el análisis informatizado de la imagen en movimiento, y por otro, una sistematización definida y clara de las indicaciones terapéuticas.

Las conclusiones extraídas de los estudios que se realizan en el campo de la cirugía de cabeza y cuello, se enfrentan a importantes dificultades de índole metodológica (1). La elaboración de estudios randomizados es prácticamente imposible en el campo de la cirugía, y sus resultados se alejan mucho de los grados de evidencia aportados por diseños que se aplican en el ámbito de la farmacología o la epidemiología. Los condicionamientos metodológicos en la cirugía de cabeza y cuello son: Los cirujanos aprendemos a hacer las cosas mejor con el tiempo. Existe una curva de aprendizaje para cada uno de los procedimientos.

1. Los cirujanos tenemos habilidades y capacidades distintas. Eso puede condicionar los resultados, cuando hay coparticipación.

2. Los procedimientos quirúrgicos son difíciles de estandarizar. Los cirujanos aportamos nuestras propias modificaciones, que a su vez deberían ser estandarizadas durante el diseño del estudio. A veces modificamos la técnica en función de los hallazgos intraoperatorios.

3. En muchas ocasiones la aleatorización en la elección de pacientes choca frontalmente con las bases éticas de cualquier estudio clínico.

4. Tanto cirujanos como pacientes "nunca permanecen ciegos" a la hora de valorar resultados, complicaciones, función, dolor o calidad de vida.

Las dificultades enumeradas dan valor a la técnica de registro y análisis presentada por el Dr. Hontanilla. Es una técnica repetible, fácil de llevar a cabo y registrar, y que fundamentalmente, no es cruenta ni molesta para el paciente. Tiene además, un valor añadido medicolegal. Los resultados medidos en distancias, ángulos, velocidad y área, se alejan de la subjetividad que aportan los sistemas clásicos de gradación de la parálisis facial, por lo que permiten ser valorados por terceros.

La depuración del análisis de los resultados permitirá, en efecto, modificar el algoritmo de decisión propuesto para el establecimiento de una estrategia terapéutica, que por el momento, se basa en dos variables: el tiempo de denervación y las características de la lesión (etiología, nivel de lesión y presencia o no del cabo proximal del nervio facial).

Echo de menos que no se hayan valorado con el sistema "Facial Clima" el grupo de técnicas que se agrupan en torno a las transferencias nerviosas desde el nervio hipogloso al facial.

Las anastomosis hipogloso-facial (HF) con conservación del hipogloso en sus diferentes modalidades, no producen ninguna alteración funcional en el movimiento de la lengua y la deglución (2). La anastomosis HF con técnica de May (neurotomía cefálica de menos de $20 \%$ antes de la emisión de la rama descendente, con interposición de injerto de auricular mayor latero-terminal a término-terminal), realizada antes de los 18 meses, produce resultados muy superiores a los INFC, en cualquiera de sus variantes. También es superior a los transplantes de músculo microquirúrgicos: hay 17 músculos potencialmente reinervables, frente al único vector de contracción que aporta el transplante muscular. La técnica de anastomosis HF consigue sistemáticamente simetría en reposo, elaboración de sonrisa social con entrenamiento y competencia en el cierre palpebral. Las sincinesias ojo-boca aparecen siempre, pero de intensidad muy variable. En la mayoría de los casos la rehabilitación facial y el uso de toxina bolutulínica, consiguen la independización parcial del movimiento oral y ocular (3).
Las anastomosis HF son el "caballo de batalla" en el tratamiento de la parálisis facial definitiva, pues consigue reinervar la mayoría de los 17 músculos de la cara paralizada. Incluso en casos de edad avanzada (por encima de los 65 años) es una técnica superior a los procedimientos estáticos y que debe ser ofrecida a los pacientes, ya que el sacrificio anatómico que se realiza es mínimo. La mayoría de las series describen resultados grado III en la escala de House-Brackmann (2).

En pacientes con denervación de más de 18 meses de evolución, la anastomosis HF con enrutamiento intrapetroso del nervio facial (extracción del nervio facial intrafalopiano hasta su primer codo), sin la utilización de injerto nervioso, sigue aportando resultados superiores al transplante muscular microquirúrgico. Aunque el tiempo de denervación sea mayor de 18 meses, la anastomosis HF con enrutamiento del nervio facial, aumenta las posibilidades de transferir axones funcionales al territorio facial a través de una sola sutura entre estructuras nerviosas con vascularización propia. Los resultados obtenidos son similares a las anastomosis HF con interposición de injerto realizadas en estadíos más precoces de denervación (4).

Debemos hacer un esfuerzo, junto con otras especialidades, para poder ofrecer a los pacientes tratamientos precoces (antes de 1 año), ya que pasado un plazo de 24 meses, solo las técnicas microquirúricas de transplante muscular pueden rehabilitar la comisura labial. A pesar de su brillantez conceptual, la técnica aporta un único vector de fuerza para sustituir al total de musculatura insertada en el modiolus comisural. Además, el paciente necesita frecuentemente tiempos quirúrgicos añadidos (reinserción del cabo muscular medial, necesidad de destensar el músculo por retracción asociada a la fibrosis y procedimientos de disminución de volumen) y no rehabilita el cierre palpebral.

Este último aspecto requiere una última valoración. Las pesas palpebrales son una herramienta de primer orden en el tratamiento del lagoftalmos paralítico. Considero que son de mucha utilidad cuando se prevé una reinervación, entendiendo que se trata de una medida provisional y reversible, a la espera de que el orbicular adquiera tono muscular.

Como técnica definitiva tiene algún inconveniente, como es la atrofia de los tejidos (ya atróficos por la dernervación) y funcionamiento "a la inversa" cuando el paciente está en decúbito supino: en muchos casos aumenta la posibilidad de dejar el ojo abierto durante la noche. En los casos donde no se espera reinervación, prefiero utilizar la técnica de transposición de temporal propuesta por Gillies modificada. Se talla menos cantidad de músculo y se añaden técnicas de alargamiento con la misma fascia profunda del músculo. Su finalidad no es un cierre activo con movimientos masticatorios, sino un cierre pasivo por la presencia de tono muscular constante, que cierra el ojo cuando el elevador deja de traccionar. Aporta dos ventajas más: el ojo se cierra durante el sueño y hace innecesario el uso de tiras de tendón para tratar el ectropion del párpado inferior. La movilización de pequeñas porciones de músculo y tomando la parte central de mismo, minimiza el efecto visual de "fosa vacía".

Por último, quiero felicitar al Dr. Hontanilla tanto por la calidad de los resultados presentados, como por el esfuerzo realizado para elaborar un algoritmo de decisión claro, basado en la experiencia clínica obtenida de los 140 casos de los que se compone la serie.

\section{Bibliografía}

1. Levis, C. and Archibald, S.: "Clinical Research in Head and Neck Reconstruction”. Clin Plast Surg 2208, 35 (2): 277.

2. May M, Sobol SM, Mester SJ: "Hypoglossal-facial nerve interpositional-jump graft for facial reanimation without tongue atrophy". Otolaryngol Head Neck Surg, 1991, 104:818. 
3. Boroojerdi B; Ferbert A; Schwarz M; Herath H; Noth J.: "Botulinum toxin treatment of synkinesia and hyperlacrimation after facial palsy". J Neurol Neurosurg Psychiatry 1998, 65(1):111.

\section{Respuesta al comentario del Dr. Pérez Luengo}

\section{Dr. Bernardo Hontanilla}

En primer lugar queremos dar las gracias al Dr. Pérez Luengo por sus siempre interesantes comentarios. Sin embargo, queremos hacer algunas apreciaciones respecto de lo apuntado por nuestro compañero. La anastomosis hipogloso-facial descrita y referenciada por el Dr Pérez Luengo provoca invariablemente sincinesias faciales importantes con movimientos en masa difíciles de corregir, aun presentando una situación facial en reposo muy aceptable. En nuestra opinión, pensamos que la anastomosis hipogloso-facial debería hacerse en el tronco cigomático, y no tan craneal en el propio nervio facial, para
4. Darrouzet V, Guerin J, Bebear JP: "New technique of side-to-end hypoglossal-facial nerve attachment with translocation of the infratemporal facial nerve". J Neurosurg 1999, 90:27.

evitar tantas sincinesias. Por otro lado, el límite de tiempo para realizar este tipo de transposiciones nerviosas pensamos que podría ser de 4 años, y no de 2 años, especialmente en mujeres jóvenes a la vista de nuestros resultados. No queremos soslayar, tal y como apunta el Dr. Pérez Luengo, la importancia de la colocación de una pesa de oro como primer eslabón quirúrgico en el tratamiento del párpado paralítico, siendo cada vez menos indicada la técnica de Gillies para la rehabilitación del párpado paralítico. De nuevo agradecemos sinceramente los comentarios del revisor de nuestro trabajo. 